\title{
EnglishLesson: Learn English in Sinhala
}

\author{
Vibhavi Artigala \\ Departement of Computer Science and Technology \\ The University of Bedfordshire
}

\author{
L. H. G. M. Lakshini \\ Departement of Computer Science and Technology \\ The University of Bedfordshire
}

\begin{abstract}
Learning the English language is taken a crucial part of Sri Lankan people's lives nowadays since it acts an essential role in their day to day lives. Nowadays, students are working on bust schedules, and they have to allocate a specific time to learn English since it's necessary for their studies and future life. Therefore, learn English through a mobile app makes it more comfortable, and the portability has also improved the comfortability of the usage. Hence the language learning through the mobile app provides efficient service to the user.
\end{abstract}

\section{General Terms}

portability

\section{Keywords}

language learning.

\section{INTRODUCTION}

\section{Project Background}

Sri Lanka is a multicultural country, and the majority of people are included in Sinhala and Sinhala is used as their mother tongue. English is considered as the secondary language in Sri Lanka. Hence the English literacy becomes a barrier to most of the Sri Lankan people. Especially school children have put less effort to learn English since the busy schedule they have. School children do not have much time to allocate only on this language because they have lots of other subjects to cover. As a solution to this problem, some mobile apps have created to learn English. However, most of those mobile applications focus on their attention only on two categories. Those are Listening, Speaking. All the instruction has given in English also. If there is a person who does not have an English literacy might be facing a problem, then. Because of these reasons, as mentioned earlier, came on forward to research this. The main point of this app is all the instructions that are provided in Sinhala to the user. That would make it easier to understand the guidance. This app also covered up the listening, writing, reading and writing by using suitable activities or descriptions. Rather than that, the mobile phone has become an essential tool for most of the user's, without any age gap and it is also trendy among the young generation. Hence the best way to produce these features as a mobile application. It enhances the usability of the system.

\section{Project Aim and Objectives}

Aim

- To develop an Android application to teach the English language using Sinhala(Mother language in Sri Lanka)

\section{Objectives}

- To identify the different lessons for user categories based on their knowledge.
- To detect existing apps that use English learning techniques.

- To identify games to interact with users to improve their English knowledge.

- To detect existing grammar checking patterns and spell checking models to check lessons.

- To design and develop the language learning app to learn English in Sinhala.

- To evaluate this language learning application.

\section{Methodology}

The methodology that had been applied to this project is Agile. Since this methodology allows future modifications with modern technology, it would be beneficial. In the agile methodology, Scrum is the approach that had been used to this project.

\section{LITERATURE REVIEW}

\section{Introduction}

In this section will demonstrate the proper literature review of how important mobile technology to learn the second languages, spell checking pattern for English language learning, how much evolved the vocabulary through the mobile application. This literature review will focus on how important the collaboratively working of mobile technology with English language learning and how it has been working on the crucial parts of English language learning through the mobile application.

\section{The Evaluation of language learning mobile app}

Since the early 1960s, advances in technologies have opened up new possibilities for learning in several ways beyond sitting in a traditional classroom. These new methods include computer-assisted, open, distance, and e-learning, in which formal and informal learning opportunities are supported [1]

To go beyond from the typical usage of mobile technology such as simple communication and entertaining tools. Therefore the researches had been decided to improve capacities, graphics, high-speed wireless connectivity, GPRS, Bluetooth, and $3 \mathrm{G}$ to find new technologies to facilitate mobile learning [1]Within the English language learning sphere, mobile application systems(apps) have transformed the mobile phone into portable language laboratories where users can learn and practice languages wherever and whenever they find an opportunity [2]

As a result of those researches, mobile learning(m-learning) become widely spread among the people without any age differences and its impact in education has grown, language learning has been enhanced by the common ownership of 
mobile devices such as phones also, media players [1]

This above approach is a part of the Open Distance Learning (ODL). Open, and Distance Learning (ODL) strives to provide compelling, efficient, engaging, and enduring learning opportunities which are dependent on improvements and developments in information and communication technologies (ICT) [3].

This flexibility in learning is cucialy critical in Open Distance Learning contexts where students, generally with limited time and resources, it is essential a flexible mode of knowledge that makes space them to study at any moment [2]

Above factors prove mobile learning ( $\mathrm{m}$ - learning) or open distance learning becomes popular because of the features which have been added to this approach from time to time. The portability, self- learning ability, easiness, enjoy from learning are getting as benefits when the mobile learning technology has become a peak level from the basement of this technology to the highest standard.

\section{IMPORTANCE OF SECOND LANGUAGE LEARNING ON MOBILE PHONE}

As mobile technology becomes more convenient and more advanced in function, researchers recommend that using mobile applications to support English language learning are appropriate. The demand for non - English speaking population to take place od English language learning skills has increased rapidly with globalization. The number of English learners has risen fast worldwide [4]. With the advanced improvement of information technology, educators have had substantial opportunities to combine the technology into language learning and that privileges the student's learning achievement [5].

These paragraphs mean the affordability, mobility has become more convenient for mobile technology and using this technology, the rapidly increasing English language learners can get supports to develop their English knowledge. With this support, students are also able to improve their language knowledge by themselves, and this affects to develop the student's language learning achievements.

Although, the technology has revolutionized with every aspect of human life and language learning is no exception. Technology has led to a new era of teaching and learning. Because it makes learning engaging, flexible, and heuristic, and technology also boosts productivity and efficiency [4]

This point mentioned above critically mentioned as mobile technology was able to fulfil every aspect of language learning through the mobile phone without any doubt. Therefore, this reason has caused to facilitate to determine language using a mobile phone and make an app with novelty features. The combination of both language learning and mobile technology has produced the most common popular mobile applications. The following table depicts the language learning mobile apps, which currently using among the language learners.
Table 1 Language Learning Mobile Apps (According to 2019 records)

\begin{tabular}{|c|c|c|c|}
\hline App Name & $\begin{array}{l}\text { App Store } \\
\text { Rating }\end{array}$ & $\begin{array}{l}\text { Google } \\
\text { Play } \\
\text { Rating }\end{array}$ & $\begin{array}{c}\text { Categor } \\
y\end{array}$ \\
\hline $\begin{array}{c}\text { Duolingo } \\
\text { (www.duolingo.com) }\end{array}$ & $\begin{array}{l}\text { 4.7 Starts } \\
616.4 \mathrm{~K} \\
\text { Ratings }\end{array}$ & $\begin{array}{c}4.7 \text { Stars } \\
7,138,73 \\
3 \\
\text { Ratings }\end{array}$ & $\begin{array}{l}\text { Langua } \\
\text { ge } \\
\text { skills }\end{array}$ \\
\hline $\begin{array}{c}\text { Memrise } \\
\text { www.memrise.com } \\
\end{array}$ & $\begin{array}{l}\text { 4.8 Stars } \\
127.7 \mathrm{~K} \\
\text { Ratings }\end{array}$ & $\begin{array}{c}\text { 4.6 Stars } \\
\text { 1,256,10 } \\
\text { 6 Rating } \\
\text { s }\end{array}$ & $\begin{array}{l}\text { Langua } \\
\text { ge } \\
\text { skills }\end{array}$ \\
\hline $\begin{array}{l}\text { Improve English: } \\
\text { Vocabulary, Grammar, } \\
\text { Word Games }\end{array}$ & $\begin{array}{c}\text { 4.8 Stars } \\
162 \text { Ratings }\end{array}$ & $\begin{array}{l}\text { 4.6 Stars } \\
\text { 44,930 } \\
\text { Ratings }\end{array}$ & $\begin{array}{l}\text { Langua } \\
\text { ge } \\
\text { skills }\end{array}$ \\
\hline $\begin{array}{c}\text { Sinhala to English } \\
\text { Speaking - English in } \\
\text { Sinhala }\end{array}$ & N/A & $\begin{array}{c}\text { 4.4 Stars } \\
490 \\
\text { Ratings }\end{array}$ & $\begin{array}{c}\text { Speakin } \\
\text { g skills }\end{array}$ \\
\hline $\begin{array}{l}\text { English Igenuma - } \\
\text { Ingreesi Igenuma in } \\
\text { Sinhala } \\
\text { http://www.kingsoftlank } \\
\text { a.com }\end{array}$ & N/A & $\begin{array}{l}\text { 4.4 Stars } \\
256 \\
\text { ratings }\end{array}$ & $\begin{array}{c}\text { Speakin } \\
\text { g skills }\end{array}$ \\
\hline
\end{tabular}

This above table explained how collaboratively working on the combination of mobile technology and English language learning together. Since mobile phones, smartphones and tablets facilitate individuals to learn whatever they wish to learn; it suits them to do so [6].

\section{THE EFFECTIVENESS OF ENGLISH LANGUAGE LEARNING MOBILE APP}

English is considered a West Germanic language, which is the second most common language in the world. Over 600 million people use English as their second language or English as a foreign language (EFL) [8]. English language learning has widely spread topic among the world, and their changes have been undergone rapidly since fast few years. When becoming mobile technology popular among the people, language learning has shown an accelerated growth with highly developed language learning tools. However, this matter is not investigated correctly yet [3]. The above paragraph is critically discussed how this combination mentioned above come together. The mobile-based language learning provides multiple side effects to the learner.

This point has been discussed about Mobile English learning: An evidence-based study with fifth graders. From computerassisted education to open learning environment, mobile technology has been developed to reduce classroom constraints during learning and to adapt learning materials based on the levels of individual students. Because of the portable devices such as smart mobile phone, students have experienced with creative teaching techniques to learn what, where, when and how they want. Therefore students have been able to do not only at school but also at out of school 
time[7]. This research makes it clear to use mobile technology to learn the English language without disrupting the busy schedules of students. The enhancement of mobile technology shows the preparation of students for studying individually except for the classroom. The mobile technology did hope to improve the vocabulary of English knowledge.

This application was a game based MEL application which has been given to identifying the zoo animals using pictures, and there were audio and video clips to use for students. This research has been used several methods to approach these learning outcomes to students.

1. Multiple choice quiz, which asked a question and gave four possible answers of which one is correct,

2. a spelling quiz, which proposed a question and gave the answer spelt in three different ways of which one is correct,

3. a memory game, where a picture and a word that represents the same object had to be matched,

4. a Yes or No game, where a question about a picture was asked what could be provided answers as either "Yes" or "No", and

5. a jigsaw puzzle, where issues could be answered by dragging tiles to the correct gap in an image.[7]

All questions and answers were represented by both text and audio. This app has been proven to give ample learning opportunities to create learning effect. It was demonstrated that time on task could be enhanced by providing the learner with an opportunity to learn in the informal context of his or her spare time [7]. The critical implication drawn from this is that primary school children give more attention to attractive teaching methods to learn a language. Students get a more precise idea about what they are studying and how the activities should complete without taking more effort.

Mobile learning technology effects better realization of any moment, freedom of complete activities in and out of the classroom, geographically separation become a reason to collaborate among students and clear connections to net and

\section{remote sensing and integration of information [9]}

Learning form mobile devices could enhance educational effects, the actual impact of mobile learning programs necessary to be enhanced by longer intervention durations, closer integration of technology with further assessment of high level skilled [10]. The critical implication drawn from this effectiveness has both good and bad side. Student can get a good idea about what he learns, and he can improve his knowledge doing several activities individually, and it makes the student can get the right decisions and do activities correctly. Although geographically separation might make student alone and that student might not be able to participate to work together because of lack of physical group activities.

\section{APPROPRIATE LANGUAGE TEACHING TECHNIQUES FOR MOBILE APP}

\subsection{Current issues in English language education}

The borders of the countries have virtually been removed as a result of the development of information technology since the English language is spoken or understood in most countries of the world. Therefore, this becomes a universally accepted language. As a result of this, this language is highly recommended for the individuals as their professional lives, their social lives and well as for their day to day activities to communicate via the English language. Because of the companies located among the different parts of the world, it is required to learn English as a second language [11]. Most non-native English learners have faced several problems during their learning sessions. Incorporating an excessive amount of decontextualized materials, unbalanced instructional emphases, i.e. predominantly teacher-centric, and emphasizing language input over language output activities, disintegrated instructions of language knowledge, i.e., listening, speaking, writing and reading skills are taught and practiced separately, lack of autonomous learning and authentic social interactions are not conducive to developing learner's communicative abilities and elevating their learning motivation [12].

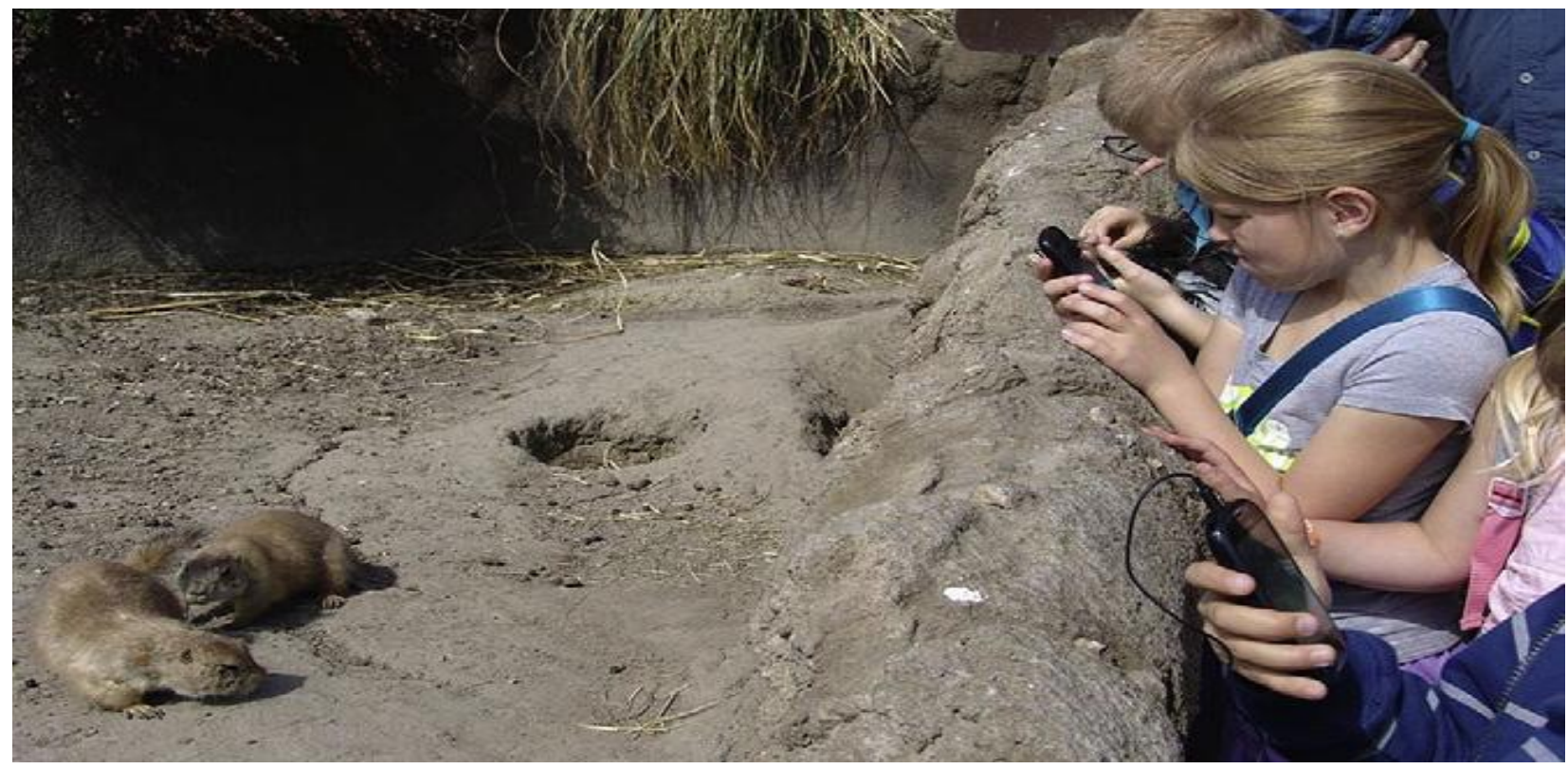

Figure 1 Some students playing with the MEL-game during their visit to the zoo [7] 

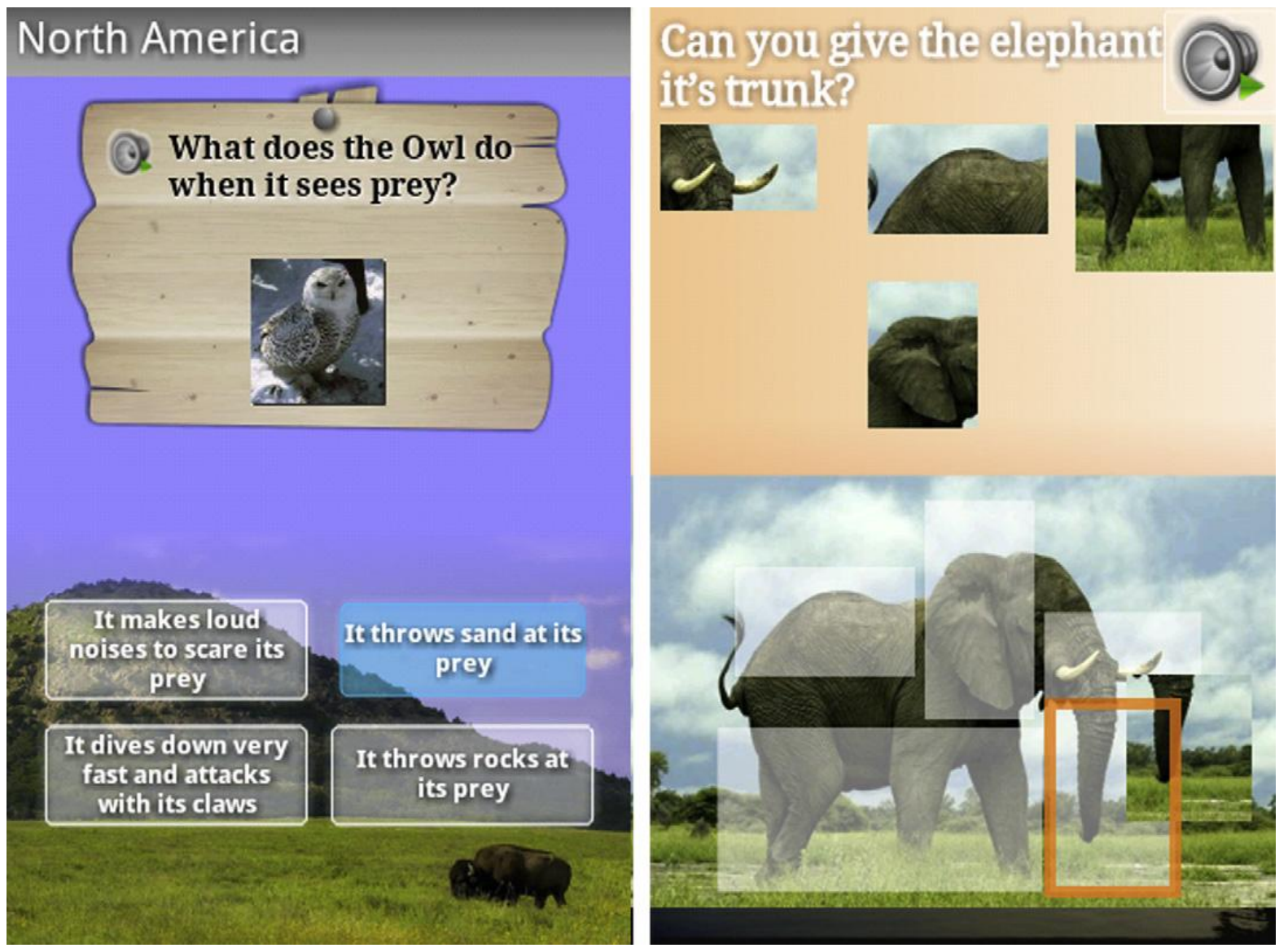

Figure 2 Snapshots from the MEL-application. On the left a multiple choice game about the Snowy Owl. On the right a jigsaw puzzle about the Elephant [7]

\subsection{Solutions}

As a solution to overcome the above problems, the mobile application language learning approach has introduced. Learn a language via mobile application is a successful method all over the world. Using video clips or voice record can be enhanced by the use of learner's own devices. This matter helps to increase learner's autonomy by allowing users to make decisions about pausing, rewinding and the use of subtitles. This practice may provide more focus, less distracted listening or video watching environment than a single teacher -controlled the central player.

As learners go on to discuss their responses to, and comprehension of reading, listening alternatively, video texts, and their spoken discussion can be recorded and used to provide feedback or analyzed for further work on communication activities in a subsequent lesson [13].

To improve English communication, it is also essential to develop the proper language pronunciation to speak in English as like as a native English speaker. An intelligent educational system is such a system that can adapt itself to the learning environment by changing the teaching methods to suit best to the learners' abilities[11]. This is, again become a solution for the above problem.

There are several mobile applications have been created to improve English knowledge in Sri Lanka. Following table represents the existing systems which are used to learn English in Sinhala.
Table 2 Comparison of some selected features with existing applications.

\begin{tabular}{|c|c|c|c|c|c|}
\hline $\begin{array}{c}\text { Function } \\
\text { s }\end{array}$ & $\begin{array}{c}\text { English } \\
\text { in } \\
\text { Sinhala: } \\
\text { Sinhala } \\
\text { to } \\
\text { English } \\
\text { Speaking } \\
\text { [14] }\end{array}$ & $\begin{array}{c}\text { Sinhala } \\
\text { to } \\
\text { English } \\
\text { Speaking } \\
\text { - English } \\
\text { in } \\
\text { Sinhala } \\
\text { [15] }\end{array}$ & $\begin{array}{c}\text { English } \\
\text { Igenuma } \\
{[16]}\end{array}$ & $\begin{array}{c}\text { Speak } \\
\text { English } \\
\text { from } \\
\text { Sinhala: } \\
\text { Sinhala } \\
\text { to } \\
\text { English } \\
\text { [17] }\end{array}$ & $\begin{array}{c}\text { English } \\
\text { Learning } \\
\text { In Sinhala } \\
{[18]}\end{array}$ \\
\hline $\begin{array}{l}1 . \\
\text { Provide } \\
\text { voice } \\
\text { records } \\
\text { to learn } \\
\text { speaking } \\
\text { English. }\end{array}$ & Provided & Provided & $\begin{array}{c}\text { Not } \\
\text { Provided }\end{array}$ & Provided & $\begin{array}{c}\text { Not } \\
\text { Provided }\end{array}$ \\
\hline $\begin{array}{c}2 . \\
\text { Provide } \\
\text { fun } \\
\text { games to } \\
\text { learn } \\
\text { English. }\end{array}$ & $\begin{array}{c}\text { Not } \\
\text { Provided }\end{array}$ & $\begin{array}{c}\text { Not } \\
\text { Provided }\end{array}$ & $\begin{array}{c}\text { Not } \\
\text { Provided }\end{array}$ & $\begin{array}{c}\text { Not } \\
\text { Provided }\end{array}$ & $\begin{array}{c}\text { Not } \\
\text { Provide }\end{array}$ \\
\hline $\begin{array}{c}\mathbf{3 .} \\
\text { Provide } \\
\text { English } \\
\text { phrases }\end{array}$ & $\begin{array}{c}\text { Not } \\
\text { Provided }\end{array}$ & $\begin{array}{c}\text { Not } \\
\text { Provided }\end{array}$ & Provided & Provided & Provided \\
\hline
\end{tabular}




\begin{tabular}{|c|c|c|c|c|c|}
\hline $\begin{array}{c}\text { and } \\
\text { explain } \\
\text { in } \\
\text { Sinhala. }\end{array}$ & & & & & \\
\hline $\begin{array}{c}4 . \\
\text { Provide } \\
\text { quizzes } \\
\text { to test } \\
\text { the } \\
\text { improve } \\
\text { ments. }\end{array}$ & $\begin{array}{c}\text { Not } \\
\text { Provided }\end{array}$ & Provided & $\begin{array}{c}\text { Not } \\
\text { Provided }\end{array}$ & Provided & Provided \\
\hline $\begin{array}{c}5 . \\
\text { Provide } \\
\text { activities } \\
\text { for } \\
\text { competiti } \\
\text { ve } \\
\text { exams. }\end{array}$ & Provided & $\begin{array}{c}\text { Not } \\
\text { Provided }\end{array}$ & $\begin{array}{c}\text { Not } \\
\text { Provided }\end{array}$ & $\begin{array}{c}\text { Not } \\
\text { Provided }\end{array}$ & $\begin{array}{c}\text { Not } \\
\text { Provided }\end{array}$ \\
\hline
\end{tabular}

According to the table mentioned above provides methods that have been used to teach the English language via mobile applications to learn this second language without any barriers. These methods are not following every form, but these mobile applications follow at least one teaching technique. User cannot get all four parts (writing, reading, listening, and speaking) in English to cover up using these applications. Most of the apps trying to move focus to the spoken part of the English language.

\section{METHODOLOGY}

It is necessary to add particular grammar checker, spell checker to features which have been collaborated with apps to improve four skills of English language (Listening, Writing, Reading and Speaking) using the mobile application. While people who use English as their second language writing text, people might make errors. Therefore it is essential to identify the grammar errors and correct them as well. Grammar checking by a human is inconvenient because of resources is limited, the size of the document, and it would be challenging to do a regular basis. Hence it would be much better to convert this process as automated [8].

Therefore it is essential to use a grammar checking tool to check the grammar errors. There are AI(Artificial Intelligence) based grammar checkers online, and there is a considerable amount of grammar checking online programs, such as Grammarly, Ginger, DeepGrammar, etc. Among them, Grammarly is widely popular because it is user-friendly for English language learners [19]. Using these tools, it would make easiness to check grammar errors efficiently.

There are specified grammar checking tools in languagewise.In India, there are grammar checkers used based on different kind of languages. Punjabi grammar checker, Hindi grammar checker Urdu, Bangala grammar checker can be considered as examples of some of the grammar checkers. [20]

In this part, use to identify the types of errors and how to classify them to several sections. Frequency of error: More frequent kept into separate groups. For instance, five types of errors that occur in ESL(English as a Second Language) text, so they are classified into different groups. Similar to this point, spelling and punctuation errors are prevalent also.
The validity of text: Errors should be parted based on how it makes the text invalid. As an example, the invalidity of the error is a text due to violation of grammar rules. As same as, an error of the sentence structure is invalidated due to breach of sentence structuring rules. Level of a mistake, nature of error and error type overlap are taken as the remaining classification of errors [8]. There is another way to classify the errors according to their means.

Sentence structure errors, punctuation error, spelling error, syntax error and under the syntax error, there is another classification. Subject-verb agreement error, article or determiner error, noun- number error, verb tense or verb form error and preposition error. Finally, the semantic error is taken to error classification. [8]There are three main techniques for grammar checking.

1. Rule-based technology: This technique is a rulebased grammar checking method, which the rules are defined by linguistic experts[8].

2. Machine learning based technology: This method is currently the most popular technique for grammar checking. In this method, statically analysis of the text to automatically detect and correct the error[8]

3. Hybrid technique: A combination of both rule-based and machine learning based methods are used to utilize to improve the system [8].

\section{CONCLUSION}

Considering the factors that have been discussed earlier, mobile language learning technology is born at once. Mobile technology has developed gradually with other techniques. This language learning processes through a mobile device is going significant place nowadays because the English language considered as the second most common language in the world. English is essential for professional works, day to day life activities. Using Mobile learning technology, this necessity would be able to make it easier.

\subsection{Research Gap}

There is currently an existing mobile application in Sri Lanka which is used to learn English in Sinhala. The comparison with the proposed application with the existing apps, the final result represents in the following table.

Table 3 Comparison of the proposed system with existing systems.

\begin{tabular}{|c|c|c|c|c|}
\hline Functions & $\begin{array}{c}\text { English in } \\
\text { Sinhala: } \\
\text { Sinhala to } \\
\text { English } \\
\text { Speaking } \\
{[14]}\end{array}$ & $\begin{array}{c}\text { Mobile } \\
\text { English } \\
\text { learning: } \\
\text { An } \\
\text { evidence- } \\
\text { based } \\
\text { study with } \\
\text { fifth } \\
\text { graders[12] } \\
\text { (Sandberg, } \\
\text { Maris and } \\
\text { de Geus, } \\
\text { 2011) }\end{array}$ & $\begin{array}{c}\text { Learning } \\
\text { English } \\
\text { using } \\
\text { children's } \\
\text { stories in } \\
\text { mobile } \\
\text { devices }\end{array}$ & $\begin{array}{c}\text { EnglishLesson: } \\
\text { An application } \\
\text { for learning } \\
\text { English in } \\
\text { Sinhala. }\end{array}$ \\
\hline $\begin{array}{c}\text { 1. Provide } \\
\text { voice records } \\
\text { to learn } \\
\text { speaking }\end{array}$ & Provided & Provided & Provided & Provided \\
\hline
\end{tabular}




\begin{tabular}{|c|c|c|c|c|}
\hline English. & & & & \\
\hline $\begin{array}{c}\text { 2. Provide fun } \\
\text { games and } \\
\text { stories to learn } \\
\text { English. }\end{array}$ & $\begin{array}{c}\text { Not } \\
\text { Provided. }\end{array}$ & Provided. & Provided. & Provided \\
\hline $\begin{array}{c}\text { 3. Provide } \\
\text { English } \\
\text { phrases and } \\
\text { explain in } \\
\text { Sinhala. }\end{array}$ & $\begin{array}{c}\text { Not } \\
\text { Provided. }\end{array}$ & $\begin{array}{c}\text { Not } \\
\text { Provided. }\end{array}$ & $\begin{array}{c}\text { Not } \\
\text { Provided }\end{array}$ & Provided \\
\hline $\begin{array}{c}\text { 4. Provide } \\
\text { quizzes to test } \\
\text { the knowledge } \\
\text { improvements. }\end{array}$ & $\begin{array}{c}\text { Not } \\
\text { Provided. }\end{array}$ & Provided & Provided. & Provided \\
\hline
\end{tabular}

\begin{tabular}{|c|l|c|c|c|}
\hline $\begin{array}{c}\text { 5. Provide } \\
\text { activities for } \\
\text { competitive } \\
\text { exams. }\end{array}$ & Provided. & $\begin{array}{c}\text { Not } \\
\text { Provided }\end{array}$ & $\begin{array}{c}\text { Not } \\
\text { Provided }\end{array}$ & Not Provided \\
\hline
\end{tabular}

\section{METHODOLOGY}

Agile methodology has been applied to develop this researchlevel mobile application since this methodology allows the developer to make changes and do modifications keep evolving with changing trends. At the beginning of the project, the developer needs to get a clear picture of the application. Then it needs to finalize the requirements of the project. After completing the requirement gathering, the developer can do the implementation and testing with the latest technologies. Finally, end the life of the project activities.

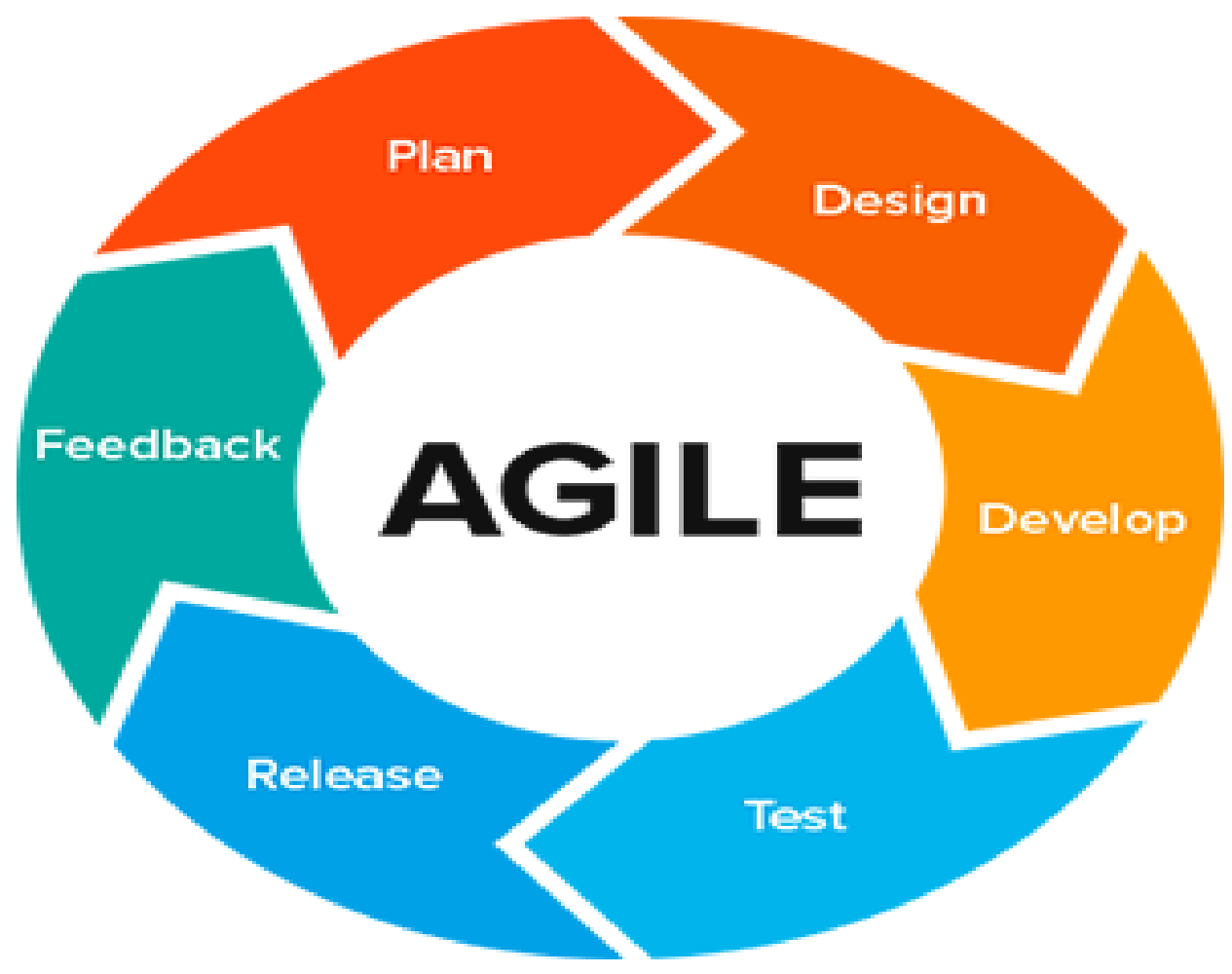

Figure 3 Agile Methodology

\section{PLANNING THE PROJECT}

At the initial stage of the project, it was necessary to plan the project. That means the time, scope and the cost. It was not required to consider the cost as a significant constraint since all the resources that have been applied to this project to are open source in this project. Initially, this mobile application had been decided to create for adults, but it was keeping to develop as a future modification because of time is the least flexible constraint in this project. Therefore, this language learning app was developed from kindergarten to secondary school kids for only. 


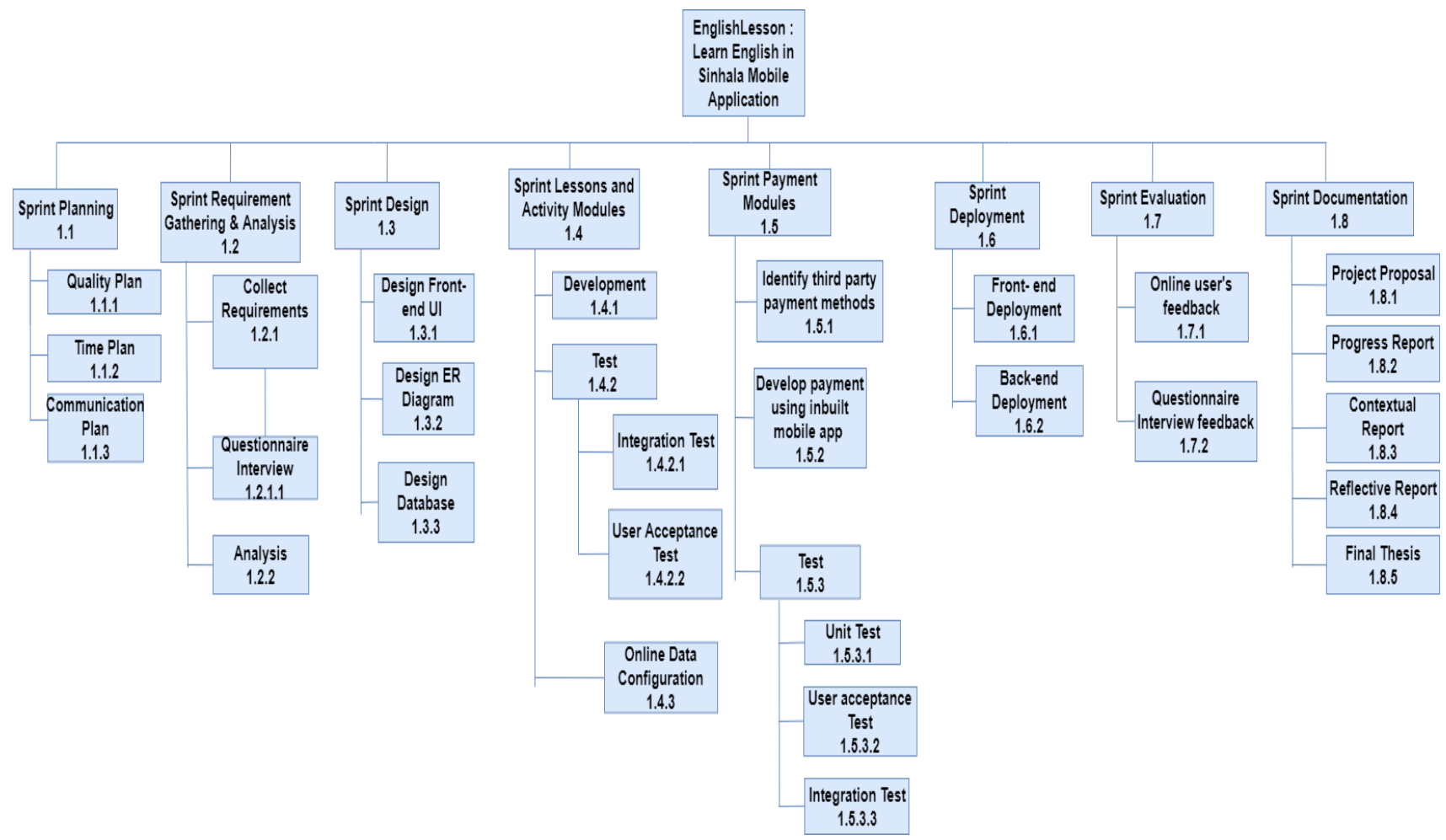

Figure 4: Work Breakdown Structure

This section will cover the proper timeline that applied to achieve the project goal using Work Breakdown Structure(WBS) and Gantt chart. Gantt chart

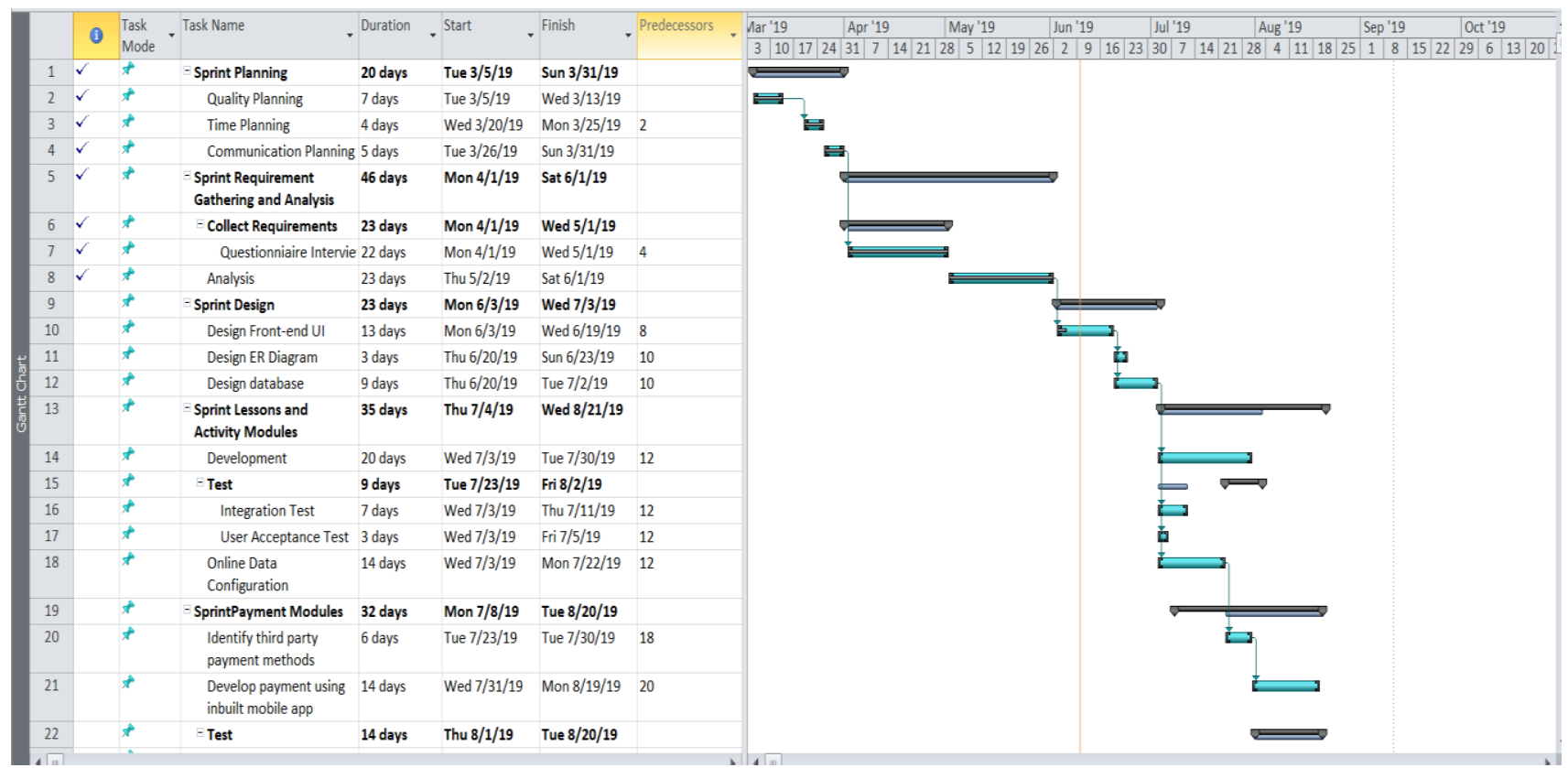

Figure 5 Gantt chart-part 1 


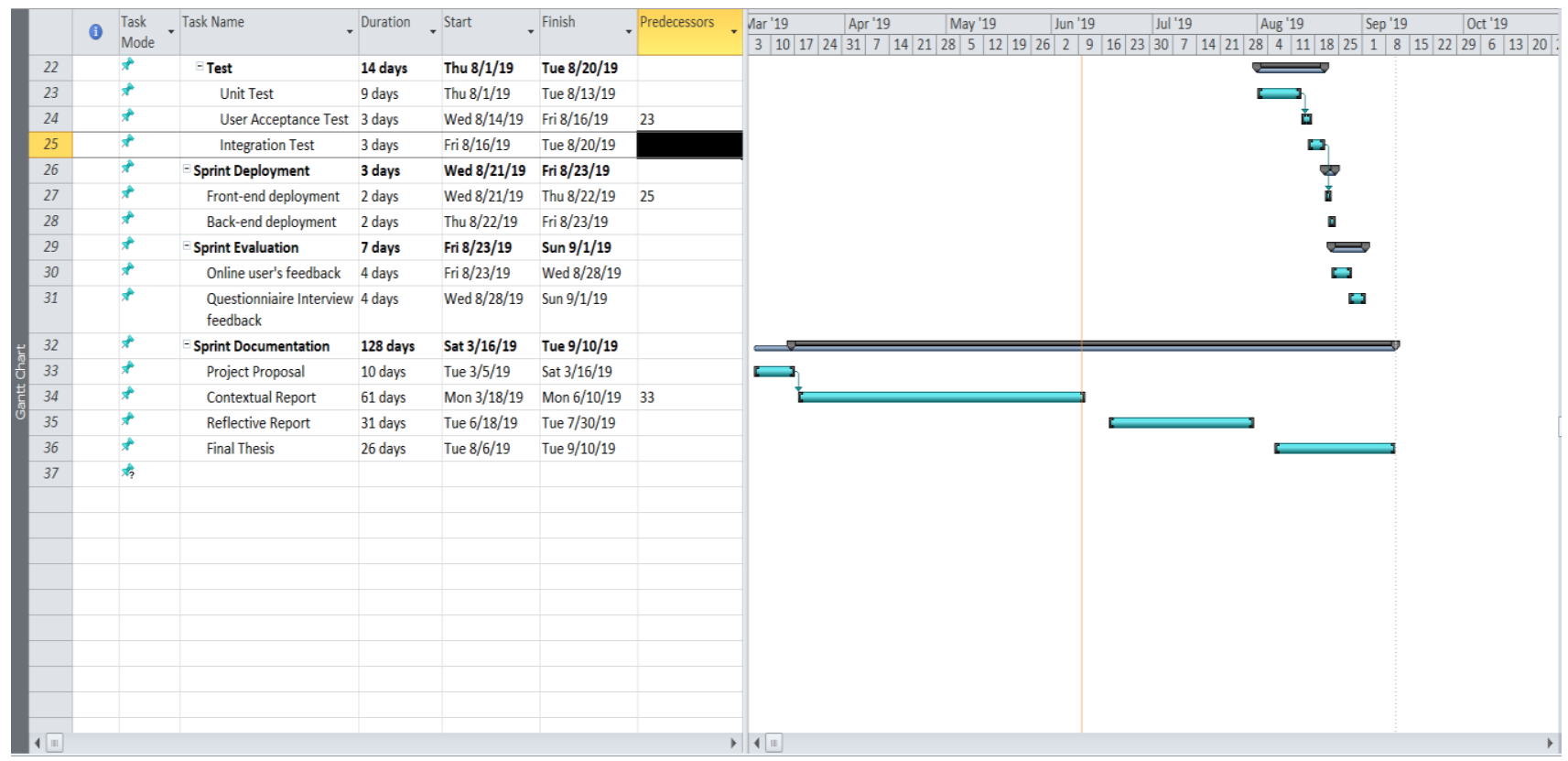

Figure 6 Gantt chart-par 6

The primary data gathering of this project was done as an interview with a selected audience. There were ten children, and ten parents participated in this interview. In this interview, the four main questions had been presented and collected the feedback from them. The primary data gathering of this project was done as an interview with a selected audience. There were ten children, and ten parents participated in this interview. In this interview, the four main questions had been presented and collected the feedback from them. After receiving the feedback from interviewers, those results were used to build the project.

Following pie charts depicts the feedback results of the interview.

\section{What do you think about learning with a mobile phone?}

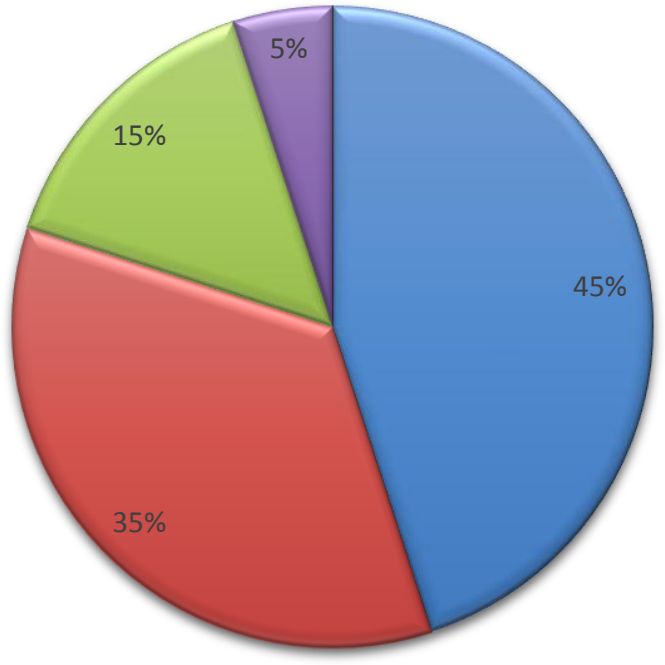

Figure 7 Chart 1 
2. Do you use a mobile phone to learn English currently?

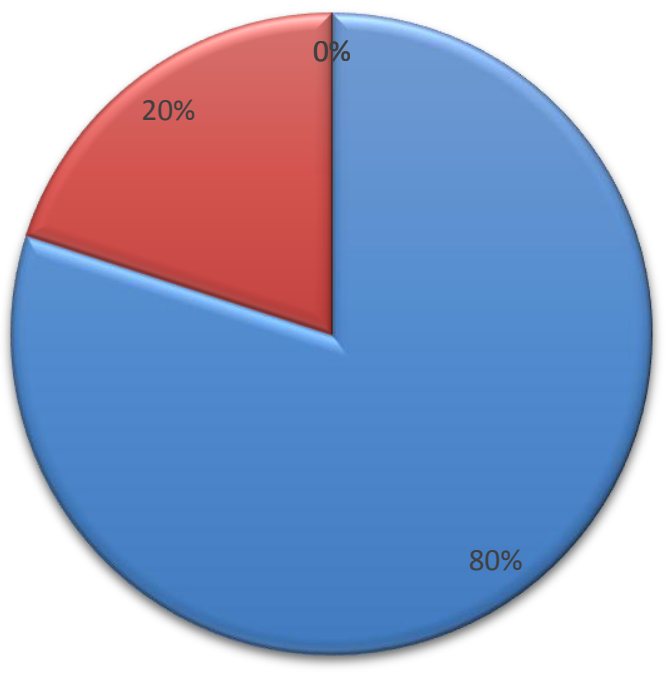

田es $\mathbf{\square}$ No

Figure 8 Chart 2

3. Which part do you more focus to learn in English?

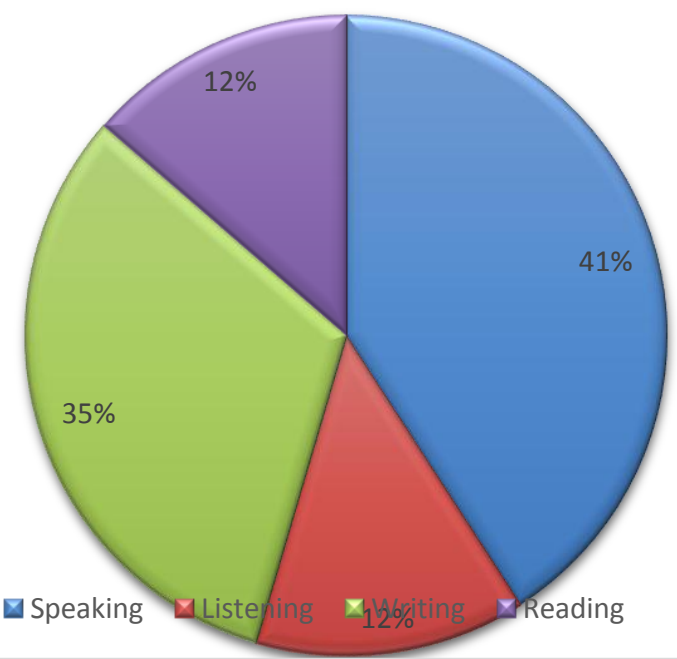

Figure 9 Chart 3 


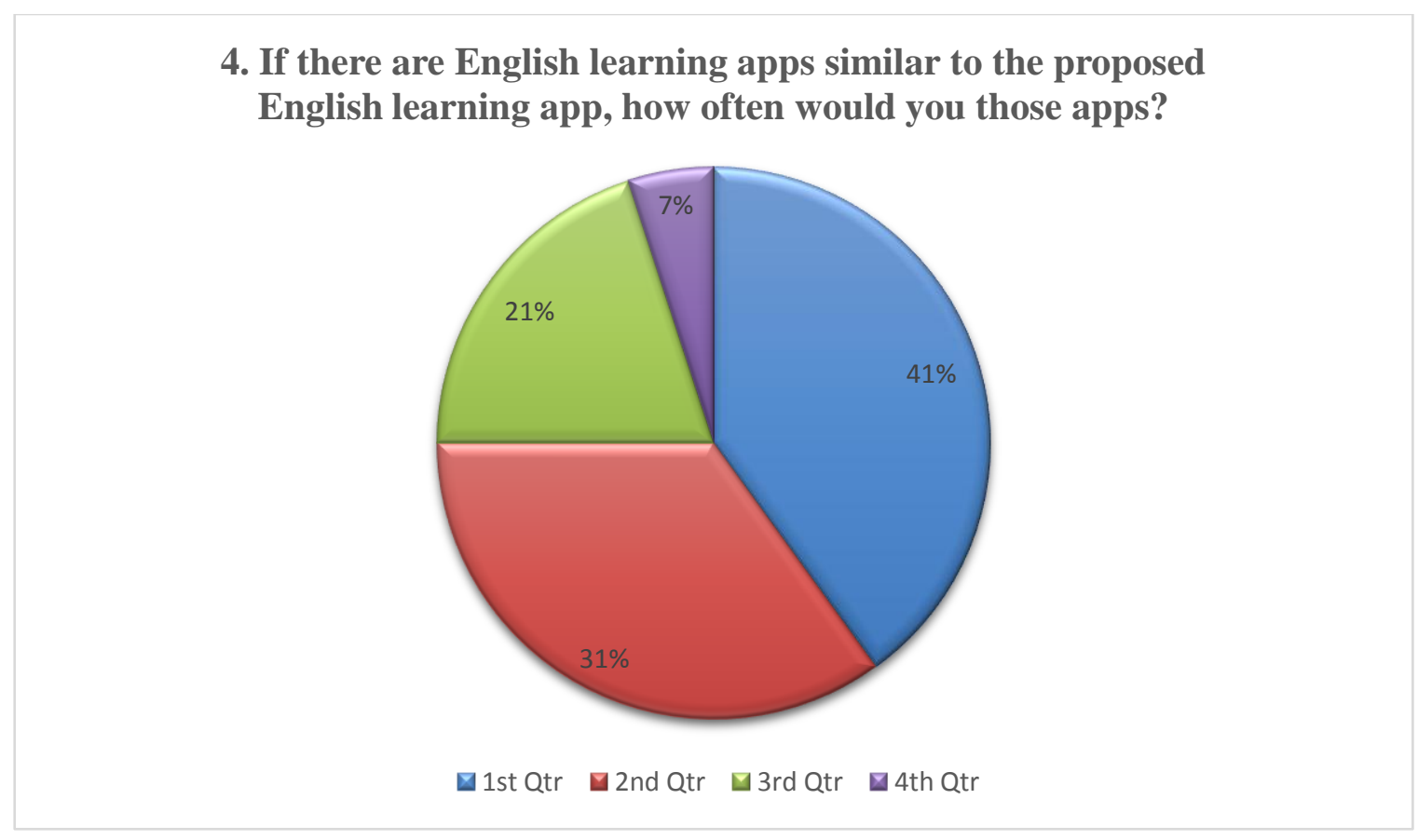

Figure 10 Chart 4

It was quickly able to get a clear image about what kind of mobile application user required using above primary data collection. As the representation of figure 7: chart 1, most of the users agreed with the mobile learning, and a slightly fair amount of users provided their feedback as it was good. The least amount of interviews had voted as mobile learning is not a good idea. Figure 8: chart 2 depicts the current percentage of using mobile technology to learn English, and the majority of interviewers voted as "Yes". In number 9: chart 3 describes the category of which would like to learn in English and most of the interviewers had given their feedback for speaking. The next highest amount is for writing, and the lowest has gone for both listening and reading categories. As the last figure 10: chart 4 portrays how often the user would use the mobile apps similar to the research level mobile application. According to that results, it says the majority of interviewers used only once a day.

The literature review was done as the secondary data gathering of the project. Research papers of the similar existing systems, related technologies and algorithms which have been applied for mobile technology had been used to collect the details to get a definite idea about the research project. As the outcome of the secondary data gathering, the literature review had been produced.

\section{DESIGN}

At the design stage, UML diagram design, UI design, had been covered.

\subsection{UML diagrams}

UML diagrams used to portray the functionalities of the system using use case diagrams, the explanation of ERdiagram and architecture diagram to describe the architectural layout of the system. These diagrams precisely rendered how the functionality works, how to add or remove several functionalities, what kind of entities need to modify, and how the system architecture should be.

\subsubsection{Use case diagram}

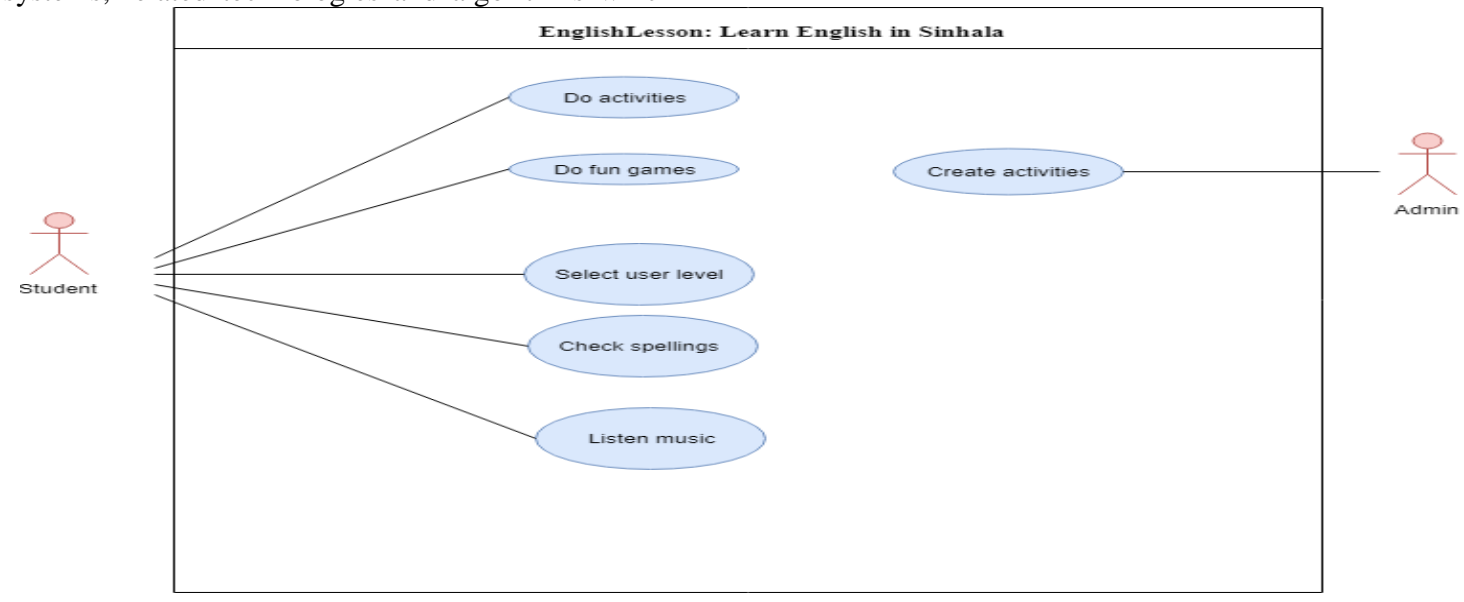

Figure 11 Use case Diagram 


\subsubsection{ER diagram}

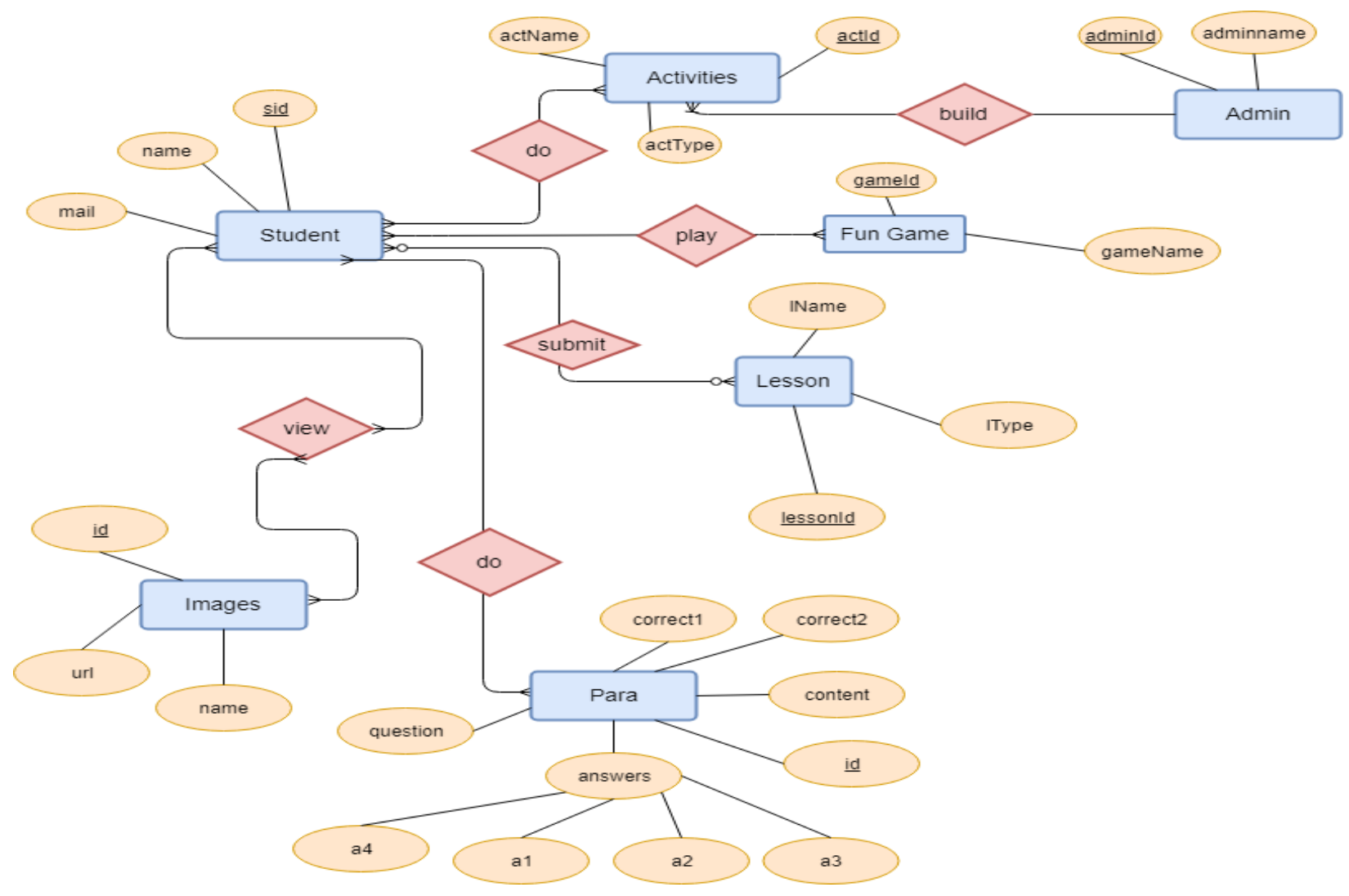

Figure 12 ER Diagram

\subsubsection{Architecture diagram}

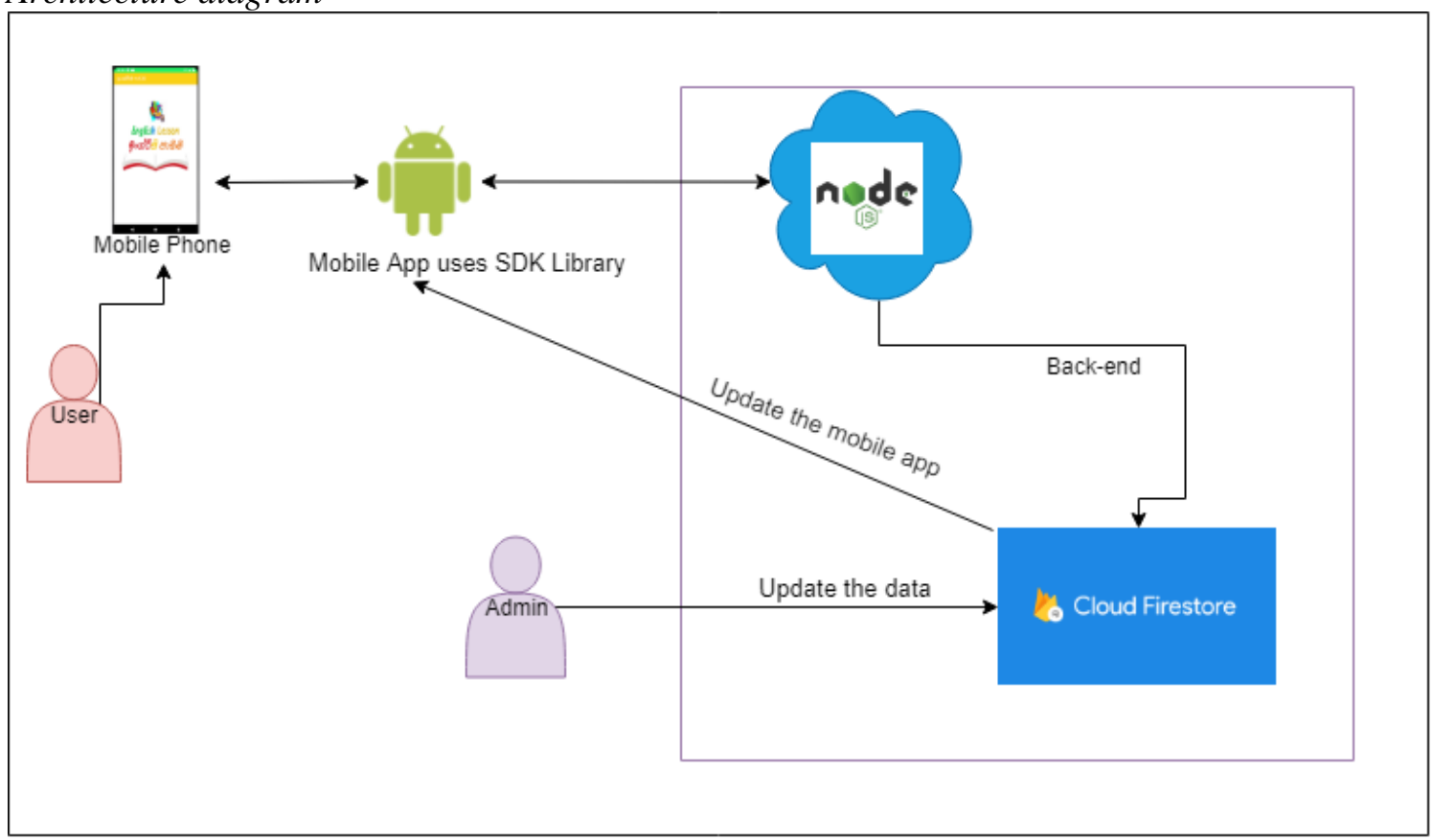

Figure 13 Architecture Diagram

This Architecture diagram shows how the infrastructure of this mobile application works. The user connects to the mobile device first. Then the mobile device starts to use the Android SDK libraries. Then the user can connect to the database through, and user retrieves the data through the web service. The admin can update the firebase data directly - the updated data real-time receive to the user. 


\subsubsection{UI design}

The user interaction part is an essential category when designing a software project, since users like interacting with colourful and attractive interfaces. In this case, students are the users of this system. Therefore, the user interfaces should have more beautiful and more vivid and should have used more images according to the content. The following shows the few user interfaces that have been created for this system.

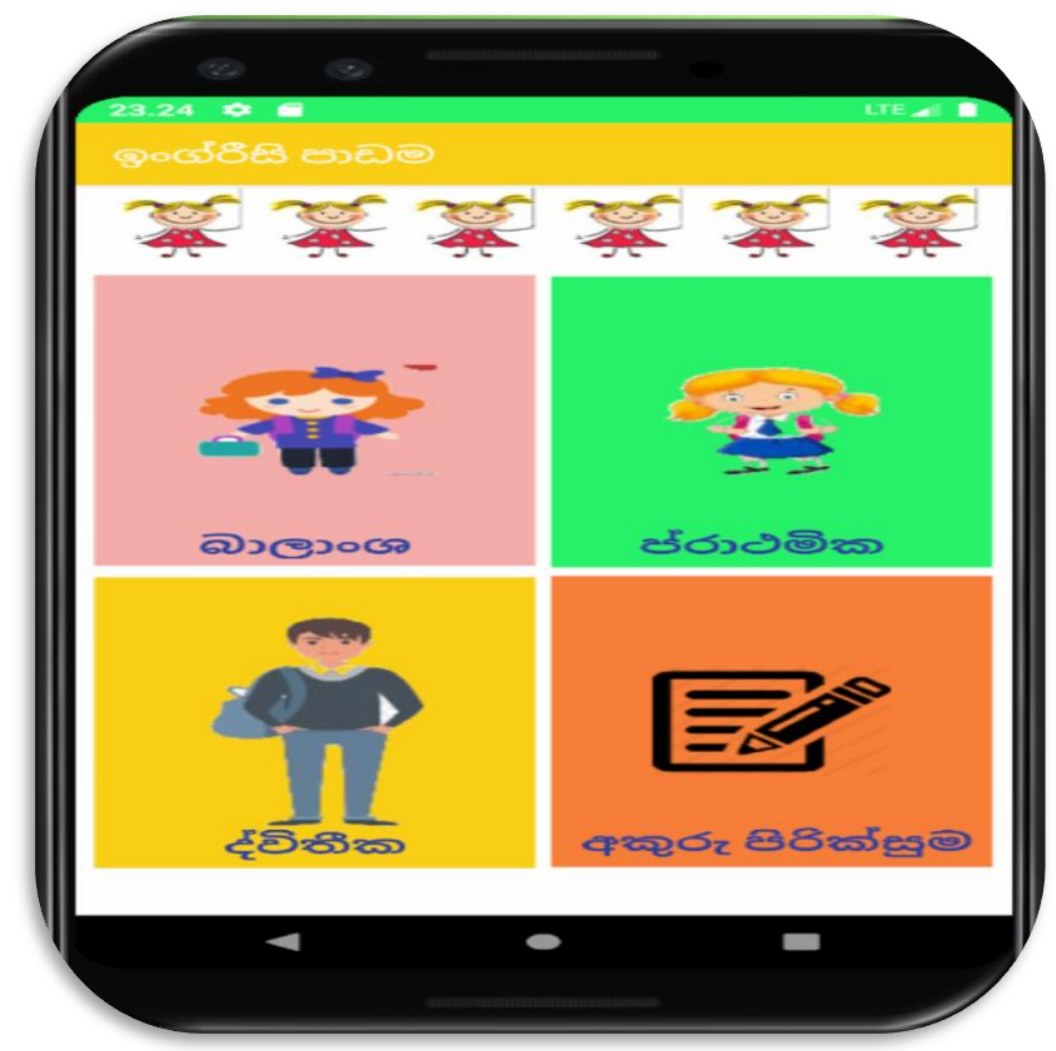

Figure 14 Home Page

this image describes the user interface of the home page of the system. After loading the system, it redirects into this home page immediately. There are four categories on this page, Kindergarten, primary, secondary and for spell checking.

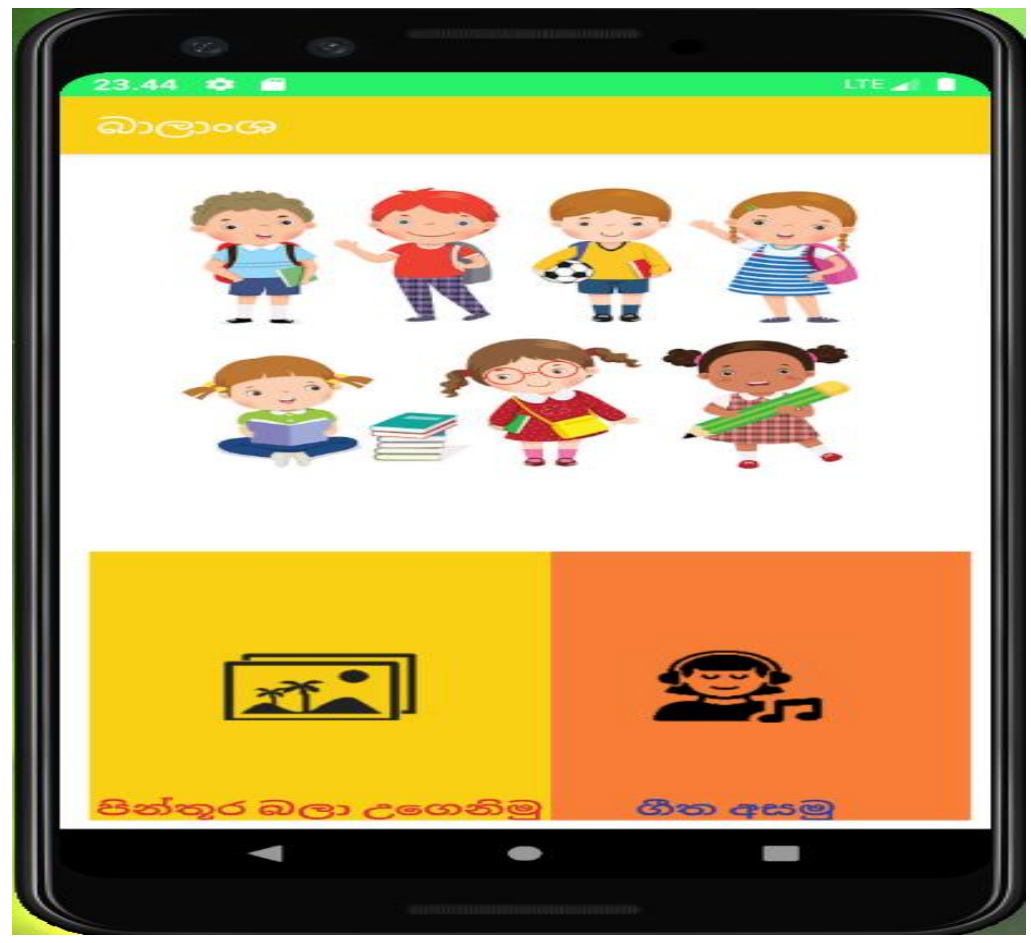

Figure 15 Kindergarten page 
Kindergarten page - this image represents the categories of kindergarten students can access, and there are two categories; one is for learning using pictures and listening songs

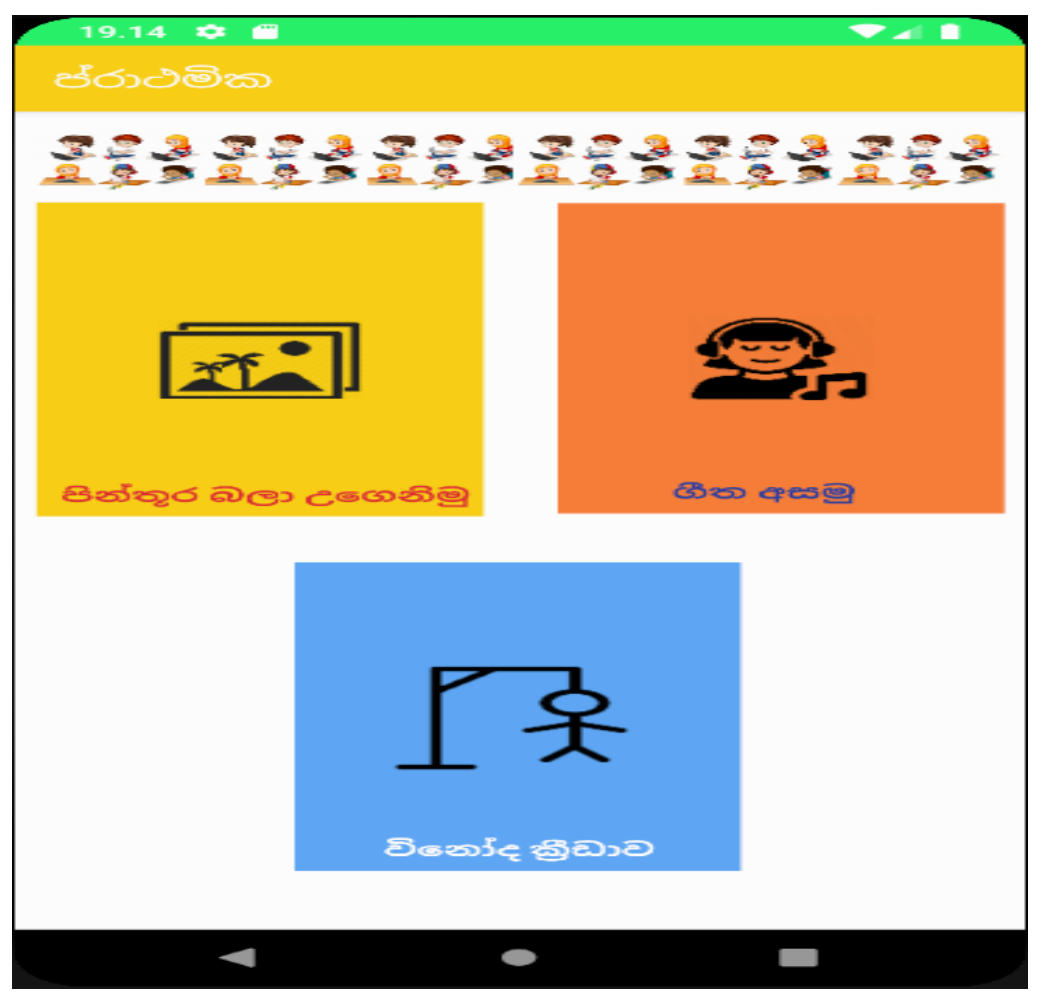

Figure 16 Primary Page

\section{IMPLEMENTATION AND TESTING}

In this section describes the implementation process of the system during the project timeline and also explains the method used to develop the project. This section will address the problems that occurred during the project implementation and how those issues solved using the possible approaches during the project. The testing phase

\subsection{Language, IDEs used for development}

There are various programming languages for developing mobile applications in nowadays. Furthermore, there are several IDEs to use to create mobile apps, as well. Java is suitable for mobile application since it is secure (not execute anything outside from JVM). It is ideal because Java supports for object-oriented paradigm. The open-source nature of Java and android is getting useful for building mobile applications. Android IDE is suitable for mobile apps which are running Android operating systems. The database of the method used Firebase since it is a real-time database and data synchronised in real-time with every connected user.

This language learning system is an android mobile app, and because of this, the IDE which used was Android studio, and the Java had been applied as the programming language to develop this mobile application. Java is the ideal language to build this mobile application, as described above. Firebase had been taken to create the database. There need to have a web service to connect this application. Node.js was used to write the web service for this project artefact.

The main component of this project is the Unicode conversion since all the guidance provides to improve the English knowledge have given in Sinhala language. Therefore the Unicode conversion has been taken the critical place in this project.

\subsection{Learn English using images \\ (kindergarten and primary students)}

It had been used Android RecycleView Adapter to display the images and to get the pictures from firebase firestore to develop this section. The recycle view is a more advanced and flexible version of the list view. The recycle view fills itself with views contributed by ListViewlayout manager that have been provided. The view holder objects represent the list views. In this case, all the images are shown as images collection, and each view holder represents a single album. The working interface can be found in Appendix A-1

\subsection{Playing Hangman game (primary and secondary students)}

This game was developed for the primary and secondary student to test their spelling ability and improve it. The words that need to be prompt in the game are taken from the Firestore database. First, get the words from the database and using the shuffle method in Collection class all the words retrieving from the database. After prompt that the word should be removed from the already defined Array List. Then that word is initialized to char array. Then add the underscore for blank spaces. These are a few steps that used to build this game. [21]

There were seven methods to apply to finalize this whole game. Finally, AnimationUtils was used to do the scale and rotate animation for the reset button in this game. The working interface can be found in Appendix A-2. The coding segments can be found in Appendix B-1 


\subsection{Reading paragraphs and answer questions}

In this section first need to select the paragraph which the user wants, and according to the selection, it generates the paragraph questions and answers from Firestore database. There is a method which had been used to get the paragraph, questions, and answers from the database and validate the selection that user entered. After confirming the selected answer the system will show whether the answer is correct or not. If the chosen solution is right then the selected option turns to green colour and the option chosen is wrong it turns into red colour. If the user chooses another paragraph then all the widgets are getting reset and set the new item, new answers and questions according to the article that displayed on the text area. The user can get idea about the read and understand the report and how to select a suitable answer from the paragraph. The images of working interfaces can be found in Appendix A-3, and the coding segment can be got in Appendix B-2.

\subsubsection{Learn Vocabulary}

In this section, the list of vocabulary can be seen, and the user able to learn new words using this section. The image of the working interface can be found in Appendix A-5.

\subsubsection{Listen Songs (kindergarten and primary students)}

This section has been made to listen to English songs for kindergarten and primary students. The list of songs is stored in the raw folder under created the res folder. The image of the working interface can be found in Appendix A-6.

Figure 17 Input Values

\subsection{Listening and Speaking}

In this section, the user able to listen to the voice records that given sentences and allow them to practice by themselves. The image of the working interface can be found in Appendix A-7.

\subsection{Guide grammar and Essay writing.}

In this part, the user able to get the acknowledgement of the basic grammar rules and how to write a proper essay with writing tips. Appendix A-8.

\subsection{System Limitations}

This mobile application is currently working on Android- based mobile phones only. This mobile application required a mobile device with an operating system higher than the Android version 4.0 (Icecream sandwich). Sinhala fonts must be installed to the mobile phone before starting to working with this mobile app.

\subsection{Testing}

This is an API testing done using Postman Rest client application. Before that, it was needed to write the web service, and it was done using Node.js, and Sublime editor was used as the text editor to write the script. To run the command using command prompt. In this case it's necessary connect to the Cloud Firestore database. The server using to run is localhost, and the port number is 3000 .

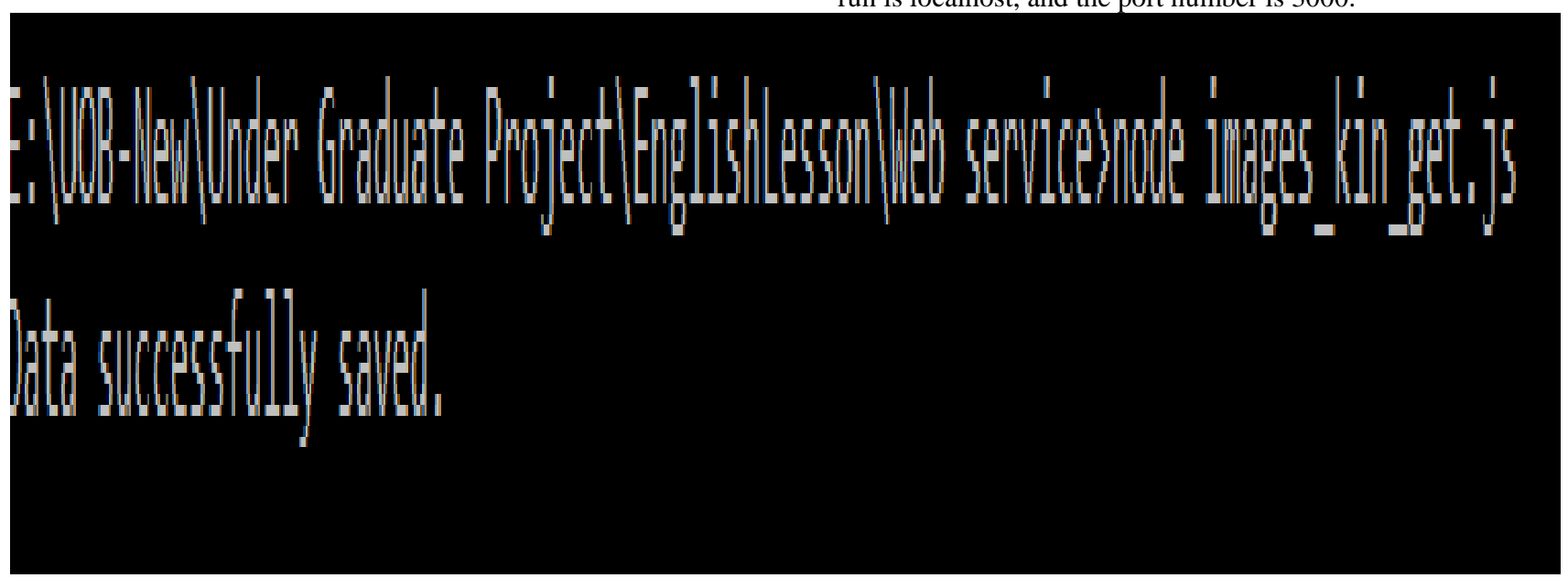

Figure 18 Actual Result 
Test case - Save data to the database.

Precondition - Connect Firestore.

Table 4 Test case 1

\begin{tabular}{|c|c|c|c|c|c|}
\hline $\begin{array}{c}\mathrm{TC} \\
\mathrm{H}\end{array}$ & $\begin{array}{l}\text { Sequen } \\
\text { ce } \\
\text { Numbe } \\
r\end{array}$ & $\begin{array}{c}\text { Test } \\
\text { Descripti } \\
\text { on }\end{array}$ & $\begin{array}{l}\text { Input } \\
\text { Value }\end{array}$ & $\begin{array}{l}\text { Expexted } \\
\text { result }\end{array}$ & $\begin{array}{l}\text { Actual } \\
\text { Result }\end{array}$ \\
\hline 1 & 1.1 & $\begin{array}{c}\text { Test the } \\
\text { data, } \\
\text { whether } \\
\text { save into } \\
\text { database } \\
\text { successfu } \\
\text { lly or } \\
\text { not. }\end{array}$ & $\begin{array}{l}\text { Figure } \\
20 \text { is } \\
\text { display } \\
\text { ed }\end{array}$ & $\begin{array}{c}\text { Data } \\
\text { saved } \\
\text { Successfu } \\
\text { lly. }\end{array}$ & $\begin{array}{c}\text { Figure } \\
18 \\
\text { display } \\
\text { ed. }\end{array}$ \\
\hline
\end{tabular}

Test case - Retrieve data from the collection called img kinder (images of kindergarten) in Firestore.

Precondition - Connect localhost with port 3000 and Firestore

Table 5 Test case 2

\begin{tabular}{|c|c|c|c|c|c|}
\hline $\begin{array}{c}\mathrm{TC} \\
\mathrm{H}\end{array}$ & $\begin{array}{c}\text { Sequen } \\
\text { ce } \\
\text { Numbe } \\
r\end{array}$ & $\begin{array}{c}\text { Test } \\
\text { Descriptio } \\
\text { n }\end{array}$ & $\begin{array}{c}\text { Inpu } \\
\text { t } \\
\text { Valu } \\
\text { e }\end{array}$ & $\begin{array}{l}\text { Expected } \\
\text { result }\end{array}$ & $\begin{array}{l}\text { Actual } \\
\text { Result }\end{array}$ \\
\hline 2 & 2.1 & $\begin{array}{l}\text { Test the } \\
\text { data } \\
\text { whether } \\
\text { retrieve } \\
\text { from } \\
\text { database } \\
\text { successful } \\
\text { ly or not. }\end{array}$ & N/A & $\begin{array}{c}\text { Data } \\
\text { retrieved } \\
\text { successfull } \\
\mathrm{y} .\end{array}$ & $\begin{array}{c}\text { Figure } \\
19 \text { is } \\
\text { displaye } \\
\text { d. }\end{array}$ \\
\hline
\end{tabular}

"statuscode": "200",

"message": "Successfully get ingges for kindergarten students.",

"result": true,

"data": [

\{

"dociD": "zpple",

"docotata": \{

"pr": 1,

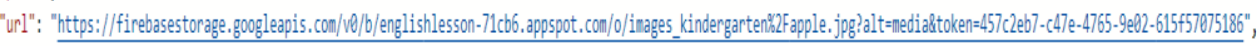

"nare": "Apple"

\}

\},

"docid": "banana",

"docData": \{

"กane": "Banana",

"pr": 2,

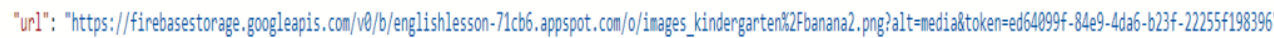

\},

"dociD": "flower",

"doclata": \{

"name": "Flower",

"pr": 3,

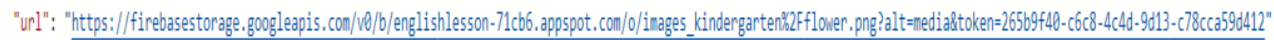

\},

"dociD": "la",

"docotata": \{

Figure 19 Data Retrieve from Images_kindergarten 
Test case - Retrieve data from the collection called img_primary (images of primary students) in Firestore.

Pre-condition - Connect localhost with port 3000 and Firestore

Table 6 Test case 3

\begin{tabular}{|c|c|c|c|c|c|}
\hline TC & $\begin{array}{c}\text { Sequen } \\
\text { ce } \\
\text { Numbe } \\
\mathrm{r}\end{array}$ & $\begin{array}{c}\text { Test } \\
\text { Descripti } \\
\text { on }\end{array}$ & $\begin{array}{c}\text { Inpu } \\
\mathrm{t} \\
\text { Valu } \\
\mathrm{e}\end{array}$ & $\begin{array}{c}\text { Expected } \\
\text { result }\end{array}$ & $\begin{array}{c}\text { Actual } \\
\text { Result }\end{array}$ \\
\hline 3 & 3.1 & $\begin{array}{c}\text { Test the } \\
\text { data } \\
\text { whether } \\
\text { retrieve } \\
\text { from } \\
\text { database } \\
\text { successful } \\
\text { ly or not. }\end{array}$ & N/A & $\begin{array}{c}\text { Data } \\
\text { retrieved } \\
\text { Successful } \\
\text { ly. }\end{array}$ & $\begin{array}{c}\text { Figure } \\
\text { 20 is } \\
\text { displaye } \\
\text { d. }\end{array}$ \\
& & & \\
& & & \\
& & & \\
\end{tabular}

\section{"statuscode": "208",}

"message": "Successfully get inages for primary students.",

"result": true,

"data": [

\{

"docid": "apple",

"doclota": \{

"nare": "Apple",

"pr": 1,

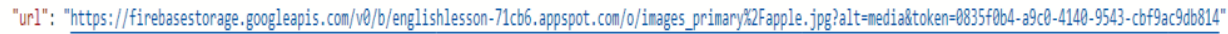


Test case - Retrieve data from the collection called para (details of paragraphs) in Firestore.

Pre-condition - Connect localhost with port 3000 and Firestore

Table 7 Test case 4

\begin{tabular}{|c|c|c|c|c|c|}
\hline TC & $\begin{array}{c}\text { Sequen } \\
\text { ce } \\
\text { Numbe } \\
\mathrm{r}\end{array}$ & $\begin{array}{c}\text { Test } \\
\text { Descripti } \\
\text { on }\end{array}$ & $\begin{array}{c}\text { Inpu } \\
\mathrm{t} \\
\text { Valu } \\
\mathrm{e}\end{array}$ & $\begin{array}{c}\text { Expected } \\
\text { result }\end{array}$ & $\begin{array}{c}\text { Actual } \\
\text { Result }\end{array}$ \\
\hline 4 & 4.1 & $\begin{array}{c}\text { Test the } \\
\text { data } \\
\text { whether } \\
\text { retrieve } \\
\text { from } \\
\text { database } \\
\text { successful } \\
\text { ly or not. }\end{array}$ & N/A & $\begin{array}{c}\text { Data } \\
\text { retrieved } \\
\text { Successful } \\
\text { ly. }\end{array}$ & $\begin{array}{c}\text { Figure } \\
21 \text { is } \\
\text { displaye } \\
\text { d. }\end{array}$ \\
& & & \\
& & & \\
\end{tabular}

\section{EVALUATION}

To evaluate this product, majorly, two methods will be used. The first one is self-evaluation the second one is potential user evaluation. At the very beginning, the personal idea of the system will be discussed according to analyzing the project artefact. Next, the likely user will have got the chance to use and get feedback from them. After using the product by outside users, the few questions will have been provided and collect the input by answering them. After combining these two evaluations get the final idea of the system whether this system is suitable for kindergarten and school kids.

\subsection{Evaluation Assumption}

The evaluation is assumed as this presented software product is not a completed version but a prototype version of the product. This evaluation is considered that the age category of all the children participated in this evaluation below 15 years old. This evaluation is assumed that this system helped to improve the technical experience of the project developer with modern technology within the self-evaluation.

\subsection{Self-Evaluation}

The self-evaluation is the part of this evaluation process, and as the developer of this project, This system provided a benchmark based on the novelty technology which had been applied for this project and those technology supported to step f0rward to the professional work. This research helped get the experience of the Android development, how to work with Firebase since this the very first time that hade been applied Firebase as the databases for an academic level project. Node.js provided a good practice of the writing web service with new technology.Turn this self-evaluation into the shortcoming of this project, and the grammar checking part was not able to achieve as one of the role of the objective.

\subsection{User Evaluation}

In this area provide the evaluation of the potential users that they have done. Fifteen-year-old below six school children had participated in this evaluation. Then six questions were asked from them after giving the mobile app to use. Those questions are prepared using Google form, and the students gave them chances to provide the feedback separately.

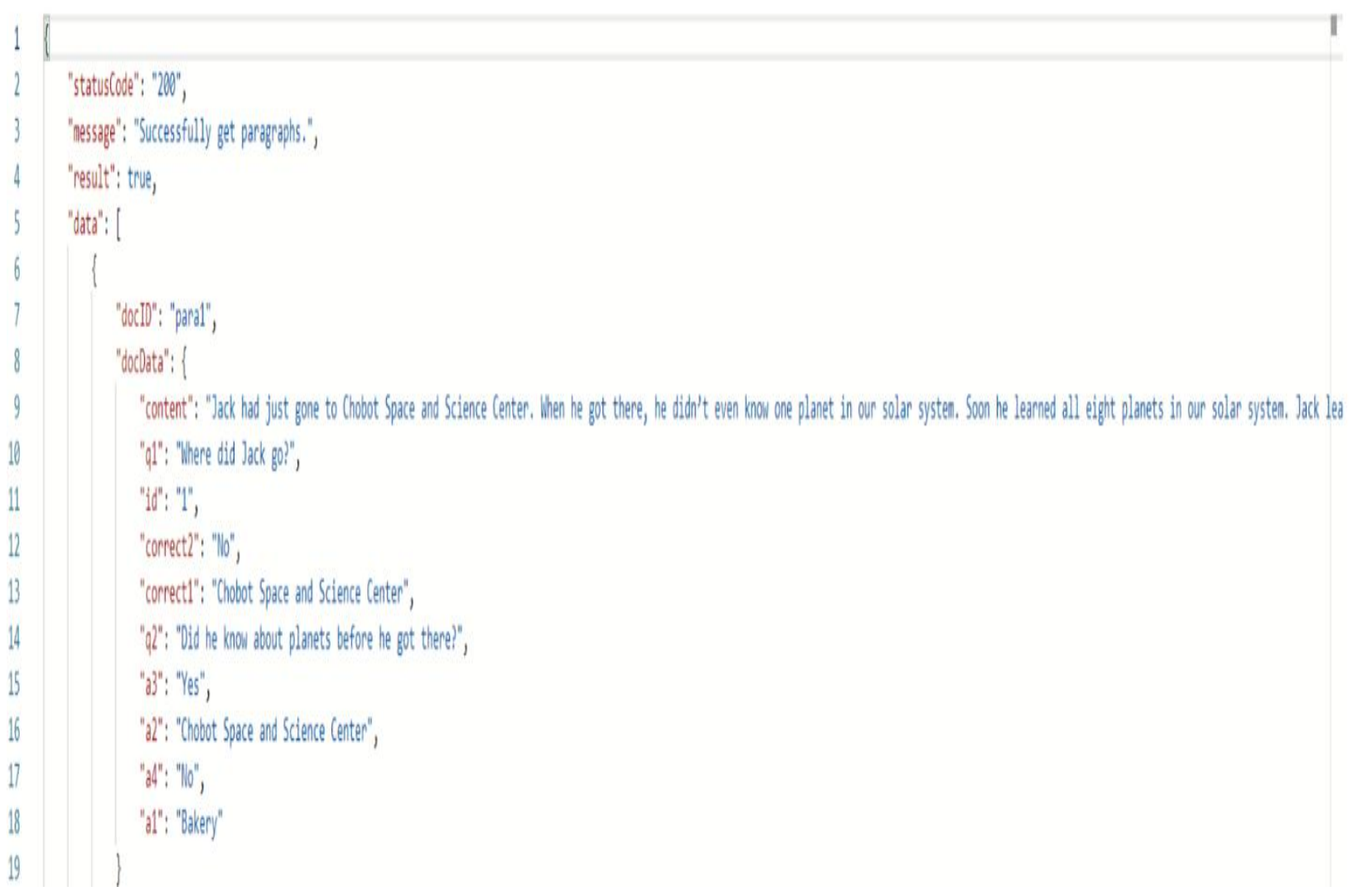

Figure 21 Actual result 
These images show the questions that had been provided for students. Question 1 was asked to check whether they have any interest in this app or check whether the first impression they got about the mobile application. Question 2 was asked to get an idea about the most exciting feature they want to work, and Question 3 was asked to get a clear picture of the essential element in this app as their perspective. Question 4 is for future medication. Since the answer got from this question would be a reason to improve the quality of the existing features and able to pay attention to adding new features. Question 5 was asked to get the satisfaction feedback from the user. Finally Question 6 was asked to get to know whether they would recommend this app or not. If so, how this product should important the improvements mentioned above for future modification purposes.

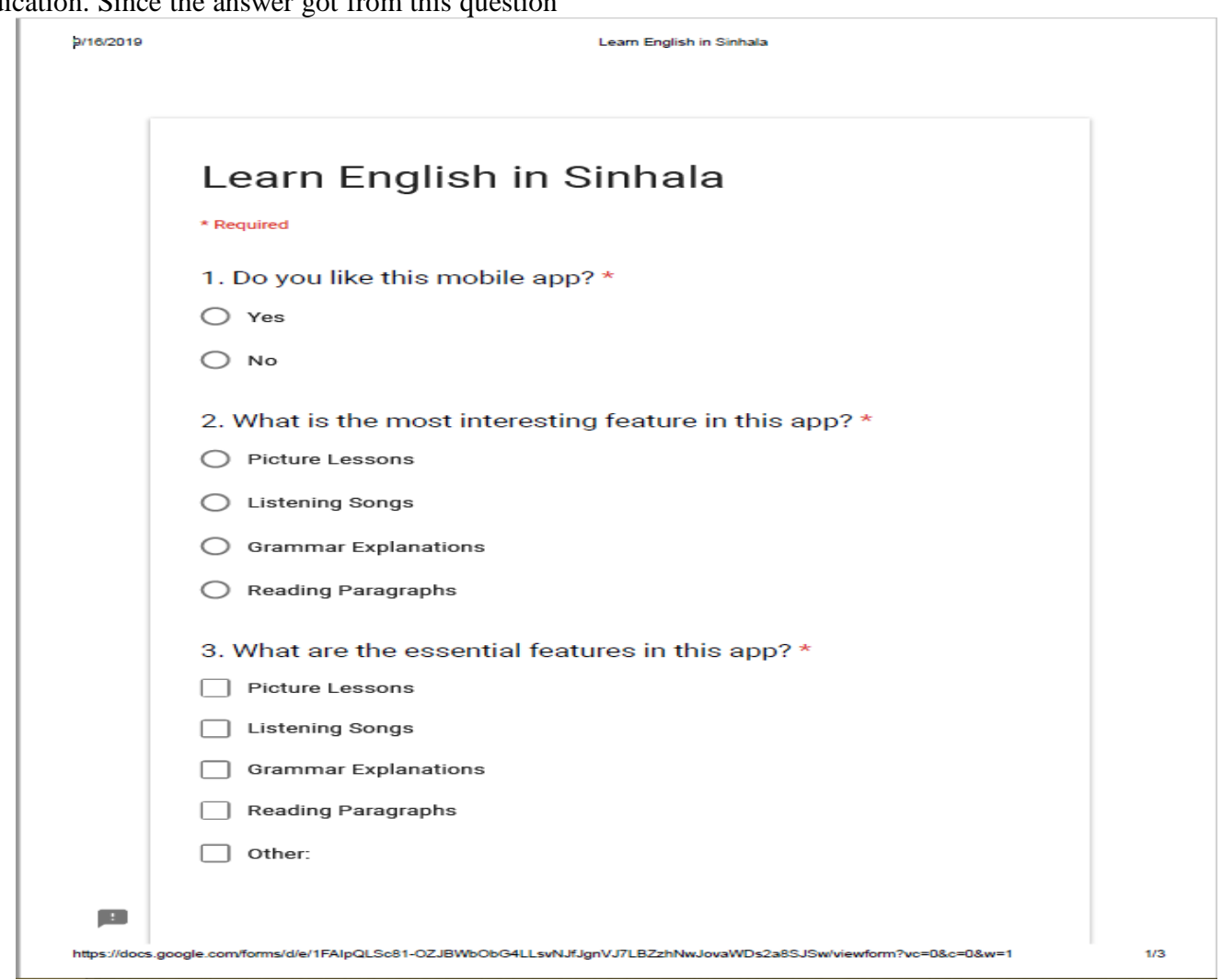

Figure 22 Survey form part-1 


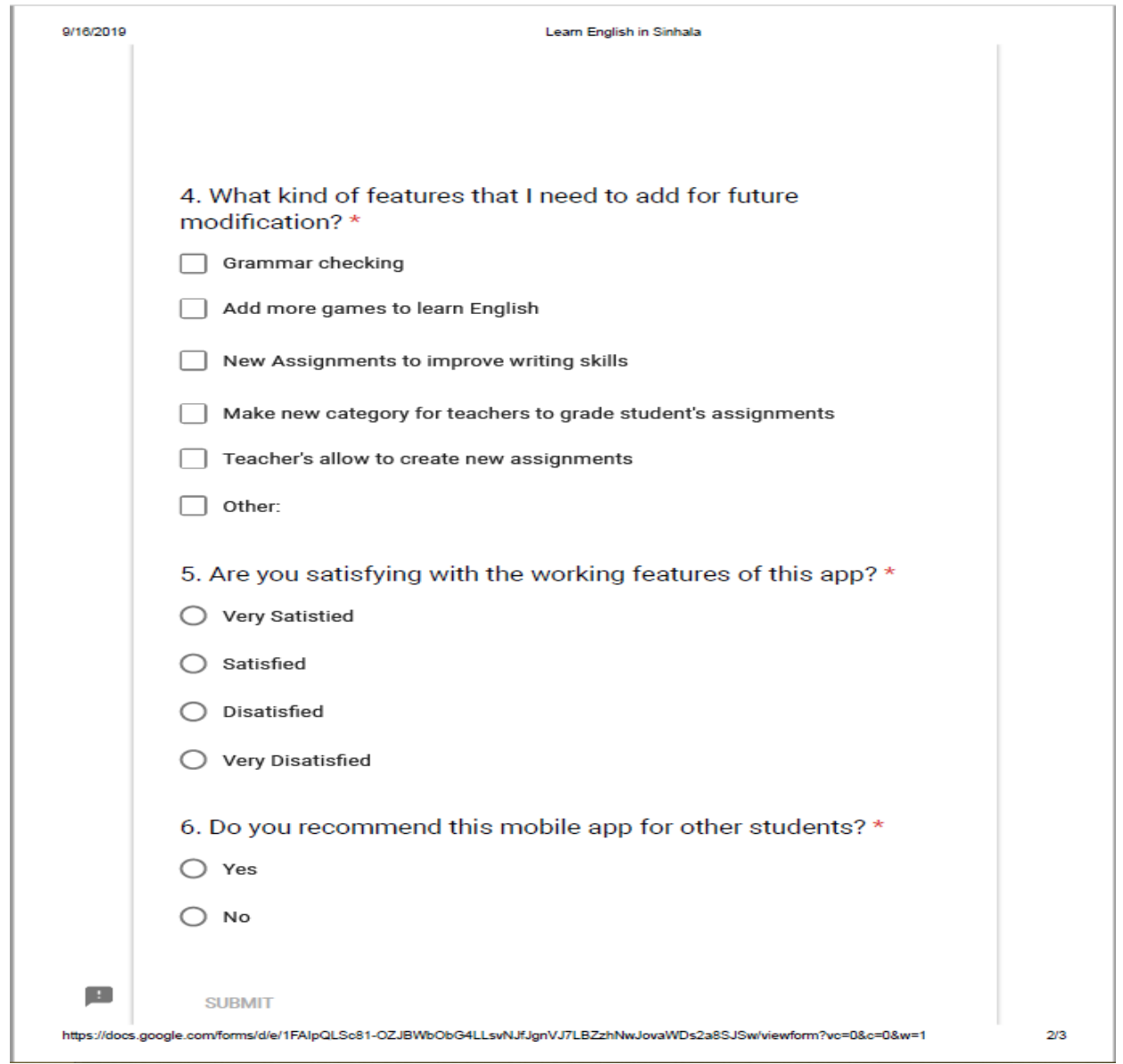

Figure 23 Survey form part-2

The following shows the finalized responses received from the user feedbacks

\section{Do you like this mobile app?}

6 responses

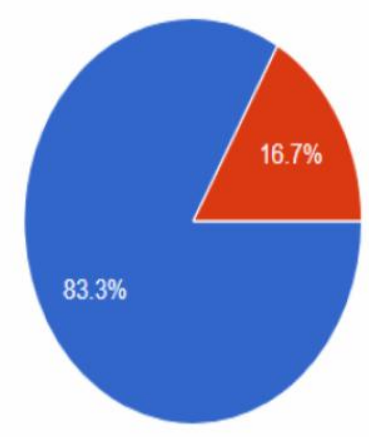


In this figure shows the final results of Question 1. According to the outcome of this pie chart, the majority voted as "Yes"

Since they had a good impression of this mobile application. $16.7 \%$ has voted "No". Since the first impression they got was not right about this mobile application.
This above figure shows the result of Question 2. According to this result, the Listen Songs part did not get any interest among users. Picture lessons feature got the votes of the majority from users.

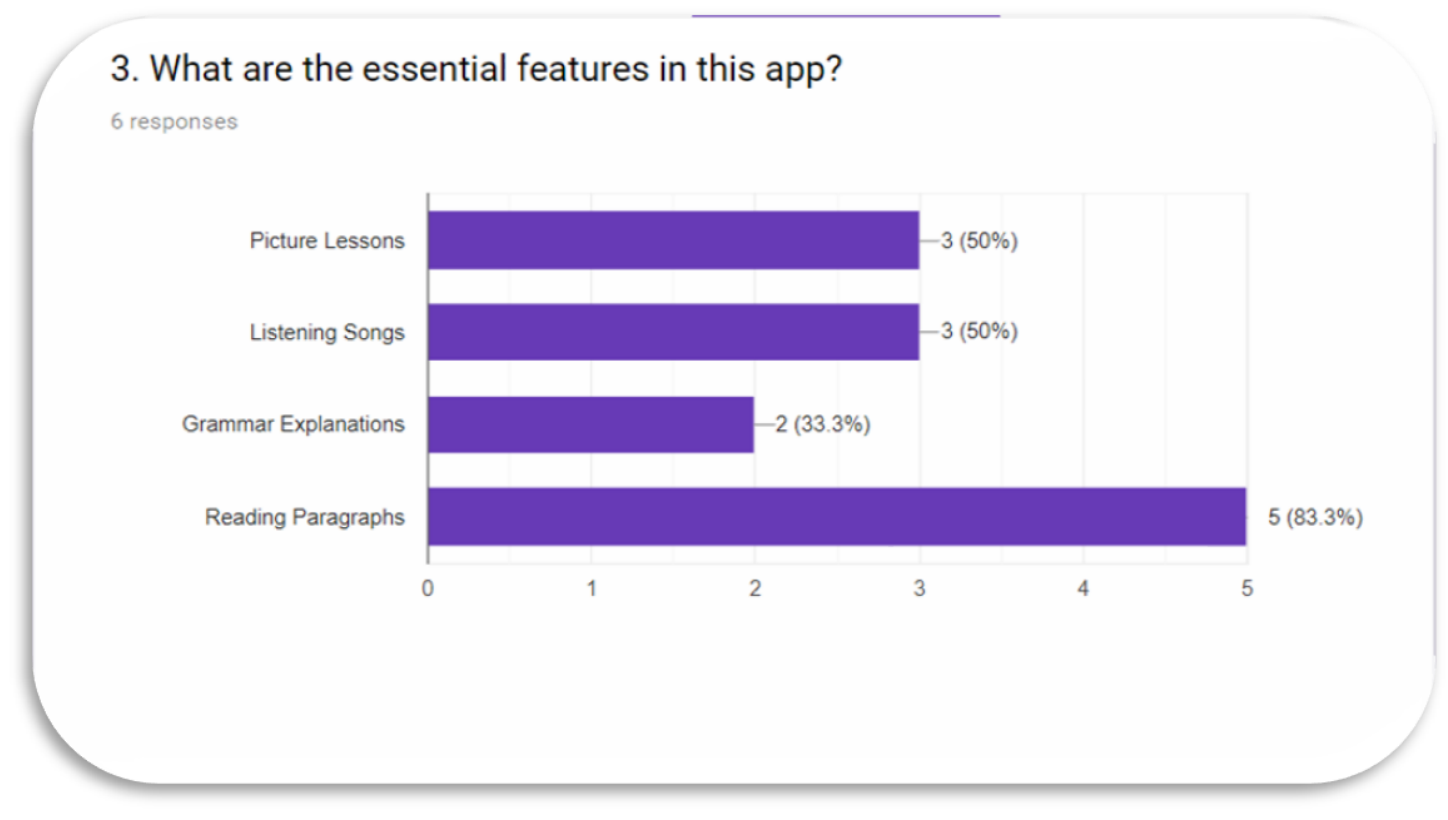

Figure 25 Chart 2

According to the result of the above picture shows the essential feature of this mobile app. Majority of users have given their votes for Reading Paragraph feature. The least amount of votes have gone for Grammar explanation. In the above figure showed the Picture lesson as a feature not much interested. But compare with the result that got for picture description in this bar char shows $50 \%$ of votes has received. That clears about Picture Lessons feature needs to improve much more to attract users in a useful manner.

\section{What kind of features that I need to add for future modification?}

6 responses

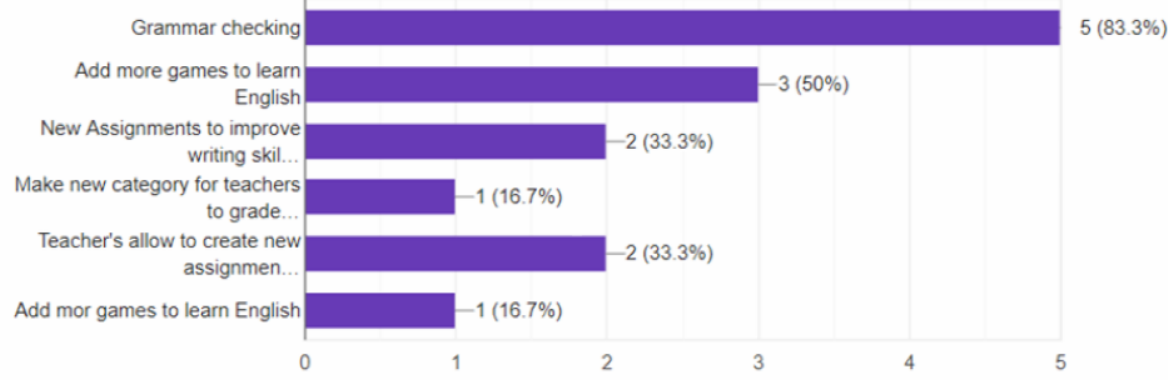

Figure 26 Chart 3 


\section{Do you recommend this mobile app for other students?}

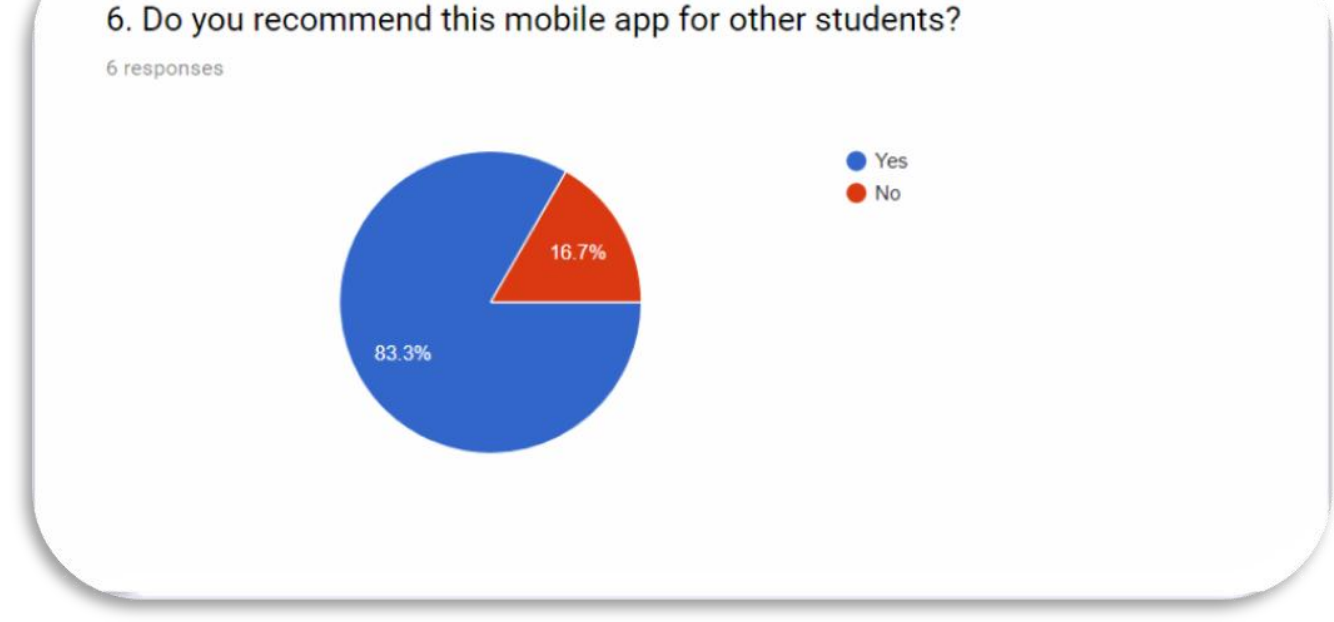

Figure 27 Chart 4

This diagram depicts features that need to add when modifying this app in future. Most of the students have given they're voted to add the Grammar checking feature for this mobile app. The next highest is Add more games to learn English, and it received 50\% voted among the students.

The above image represents result of the user's satisfaction of this mobile application. Students have provided a middlerange answer, and the majority have voted as they satisfied with this app. The other $33.3 \%$ will need to complete modifying the existing and adding new features to this mobile application.

This above picture describes whether those potential users recommend this mobile application or not. The majority of students have voted as they would approve this app for other students as well. The percentage of that value is $83.3 \%$.

\section{CONCLUSION AND FUTURE WORK}

This section will summarize the overall system, highlighted the key points discussed earlier. The next point is to describe the works that will be suggested to develop in after a time and what kind of technology and features necessary to add to this language-learning mobile application for future modification.

\subsection{Summary}

This thesis paper has recognized how this language-learning mobile application creation process worked. This paper describes at the very beginning the overall ide of this system. The next it said how data was gathered using potential users, and the secondary data gathering was done using a literature review. The methodology that has been applied to this system also explained. Then the features which the policy included and how did the testing process of this system do. The outcomes and the shortcomings that happened during the system implementation is also discussed in the previous stages.

The original idea behind this research-level project was to allowed learning English in Sinhala using mobile technology. In the beginning, this idea was spread out towards the adults also., but after starting the implementation, that part did not become quickly to implement. Since the advancement of this situation, it was created only for school children. The technology and the tools were which used this project provided better learning and professional experience.

\subsection{Future Work}

This system will be used the potential users' evaluation results to improve future modifications. As a future modification, the system will implement the grammar checking feature. The system will facilitate to teachers to create an account in this application and make the new assignments and submit them to students through the system. Students will able to get those assignments through the mobile app and complete them. If the student supposes to submit to the tutor and get to be marked, then, he or she will need to do some fair amount through the system. Otherwise, the students can send their other English assignments to be marked from teachers, and that is also be getting charged.

In the future modifications, students will be able to create their accounts and check the progress of activities they have completed in this mobile application.

The system will be developed using Flutter as a future development since Flutter is a cross-platform IDE; it is possible to build this system for iOS also in the future.

\section{REFERENCES}

[1] G. Duman, G. Orhon and N. Gedik, "Research trends in mobile assisted language learning from 2000 to 2012", ReCALL, vol. 27, no. 2, pp. 197-216, 2014. Available: $10.1017 / \mathrm{s} 0958344014000287$.

[2] M. Makoe and T. Shandu, "Developing a Mobile App for Learning English Vocabulary in an Open Distance Learning Context", The International Review of Research in Open and Distributed Learning, vol. 19, no. 4, 2018. Available: 10.19173/irrodl.v19i4.3746.

[3] A. BOZKURT and M. BOZKAYA, "Evaluation Criteria for Interactive E-Books for Open and Distance Learning", The International Review of Research in Open and Distributed Learning, vol. 16, no. 5, 2015. Available: 10.19173/irrodl.v16i5.2218.

[4] X. Chen, "Evaluating Language-learning Mobile Apps for Second-language Learners", Journal of Educational Technology Development and Exchange, vol. 9, no. 2, 2016. Available: $10.18785 /$ jetde.0902.03.

[5] R. Shih, C. Lee and T. Cheng, "Effects of English Spelling Learning Experience through a Mobile LINE APP for College Students", Procedia - Social and 
Behavioral Sciences, vol. 174, pp. 2634-2638, 2015. Available: 10.1016/j.sbspro.2015.01.945.

[6] A. Kukulska-Hulme and O. Viberg, "Mobile collaborative language learning: State of the art", British Journal of Educational Technology, vol. 49, no. 2, pp. 207-218, 2017. Available: 10.1111/bjet.12580.

[7] J. Sandberg, M. Maris and K. de Geus, "Mobile English learning: An evidence-based study with fifth graders", Computers \& Education, vol. 57, no. 1, pp. 1334-1347, 2011. Available: 10.1016/j.compedu.2011.01.015.

[8] Arxiv.org, 2019. [Online]. Available: https://arxiv.org/pdf/1804.00540.pdf. [Accessed: 10Oct- 2019].

[9] A. Fattah, "The Effectiveness of Using WhatsApp Messenger as One of Mobile Learning Techniques to Develop Students", Files.eric.ed.gov, 2015. [Online]. Available:

https://files.eric.ed.gov/fulltext/EJ1083503.pdf.

[Accessed: 10- Oct- 2019].

[10] Y. Sung, K. Chang and T. Liu, "The effects of integrating mobile devices with teaching and learning on students' learning performance: A meta-analysis and research synthesis", 2016. .

[11] N. Cavus, "Development of an Intellegent Mobile Application for Teaching English Pronunciation", Procedia Computer Science, vol. 102, pp. 365-369, 2016. Available: 10.1016/j.procs.2016.09.413.

[12] C. Chai, L. Wong and R. King, "Surveying and Modeling Students' Motivation and Learning Strategies for Mobile-Assisted Seamless Chinese Language Learning", Semanticscholar.org, 2019. [Online]. Available:

https://www.semanticscholar.org/paper/Surveying-andModeling-Students\%27-Motivation-and-for-ChaiWong/af78650caaa0ec29f1e06235308cfa8f1ac02582. [Accessed: 10- Oct- 2019].

[13] k. Hulme, "Mobile pedagogy for English language teaching: a guide for teachers", Englishagenda.britishcouncil.org, 2015. [Online]. Available: http://englishagenda.britishcouncil.org/sites/default/files/ attachments/e485_mobile_pedagogy_for_elt_final_v2.pd f. [Accessed: 10- Oct- 2019].

[14] Play.google.com, 2016. [Online]. Available: https://play.google.com/store/apps/details?id=com.englea rner.sinhalatoenglishspeaking\&hl=en. [Accessed: 10Oct- 2019].

[15] Play.google.com, 2015. [Online]. Available: https://play.google.com/store/apps/details?id=com.devel opitnowadays.sinhalatoenglish\&hl=en_US. [Accessed: 10- Oct- 2019].

[16] Play.google.com, 2018. [Online]. Available: https://play.google.com/store/apps/details?id=com.app.en gigenuma\&hl=en. [Accessed: 10- Oct- 2019].

[17] Play.google.com, 2018. [Online]. Available: https://play.google.com/store/apps/details?id=com.englea rner.listenandlearnsinhalatoenglish. [Accessed: 10- Oct2019].

[18] Play.google.com, 2019. [Online]. Available: https://play.google.com/store/apps/details?id=com.produ ction.appzone.englishbasics. [Accessed: 10- Oct- 2019].

[19] Park, J. (2019). [online] .An AI-based English Grammar Checker vs. Human Raters in Evaluating EFL Learners' Writing. Multimedia-Assisted Language Learning. Available at: http://journal.kamall.or.kr/wpcontent/uploads/2019/3/Park_22_1_04.pdf [Accessed 5 Jun. 2019].

[20] M. Mittal, D. Kumar and Sharma, Ijcait.com, 2016. [Online]. Available: https://www.ijcait.com/IJCAIT/91/911.pdf. [Accessed: 10- Oct- 2019].

[21] "Java - Setting up the project | Hangman Android App", YouTube, 2018. [Online]. Available: https://www.youtube.com/watch?v=HgH1DfH14uk\&list $=$ PLgTkNINsy9gVCkeaoudJJWr4P3Gc-AV7f. [Accessed: 10- Oct- 2019].

[22] "Java Validation: Spell Checker (Part 1)", YouTube, $2018 . \quad$ [Online]. Available: https://www.youtube.com/watch?v=AJ7RQ_jxG40. [Accessed: 10- Oct- 2019].

[23] "2.How to retrieve firebase Data into CardView and RecycleView", YouTube, 2017. [Online]. Available: https://www.youtube.com/watch?v=dth3aq_QPzU. [Accessed: 10- Oct- 2019]. 
15. APPENDIX A - THE WORKING INTERFACE OF THE SYSTEM

A-1:Learn English using images (kindergarten and primary students)

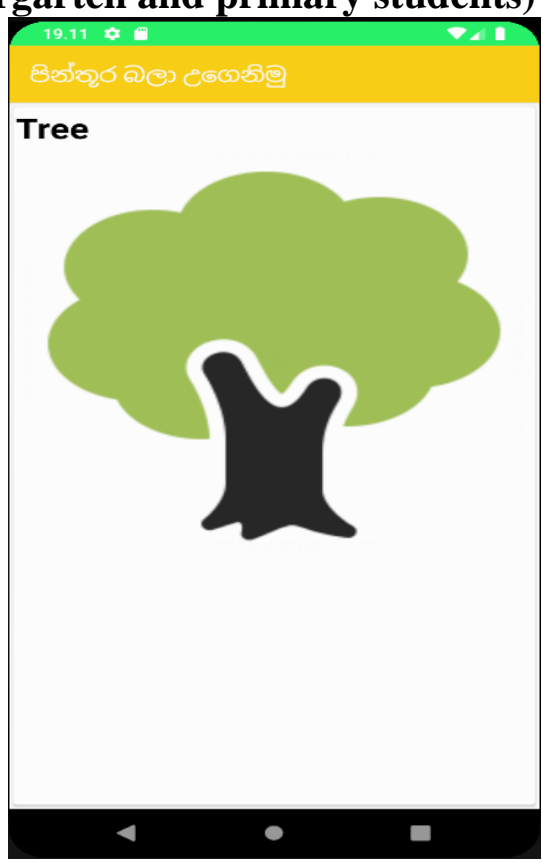

Figure 28 Picture Lessons[23]

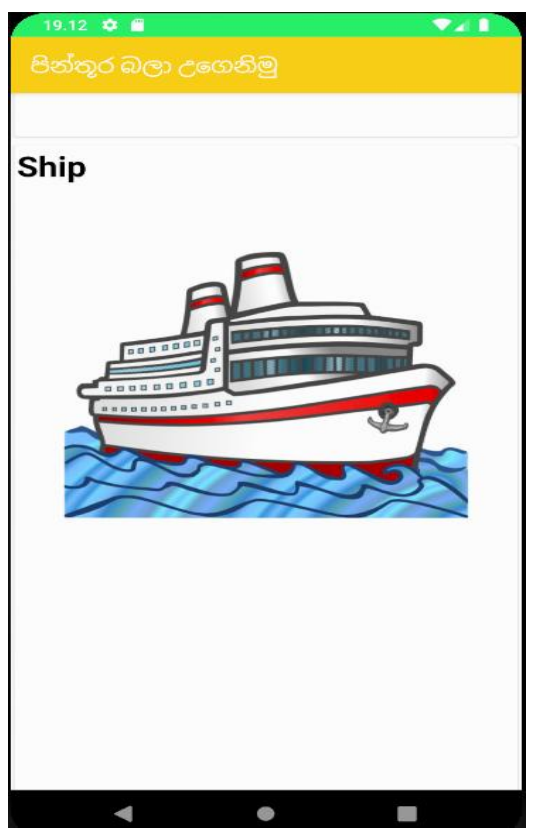

Figure 29 Picture Lessons[23]
A-2:Playing Hangman game (primary and secondary students)

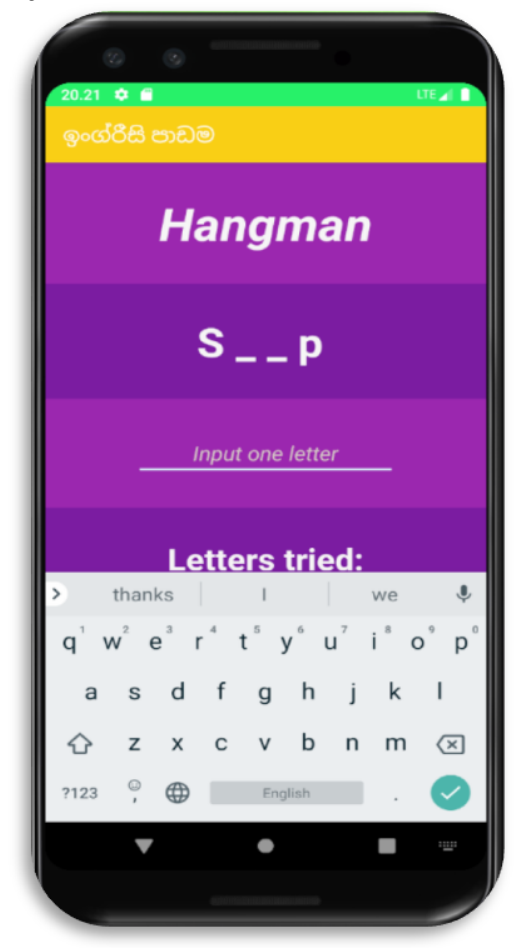

Figure 30 hangman game[21]

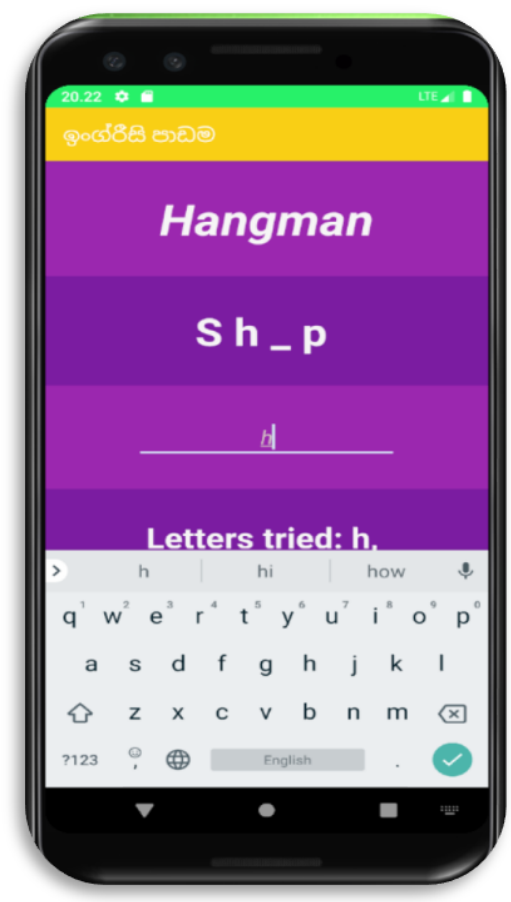

Figure 31 Hangman game[21] 


\section{A3: Reading paragraph and answer questions}

\section{A-4: Spell checking for sentences}

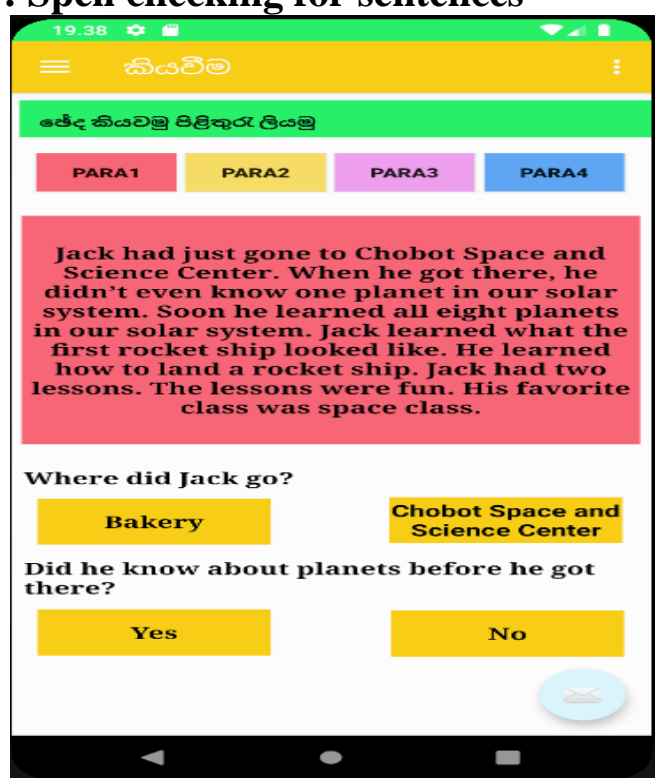

Figure 32 Paragraph reading

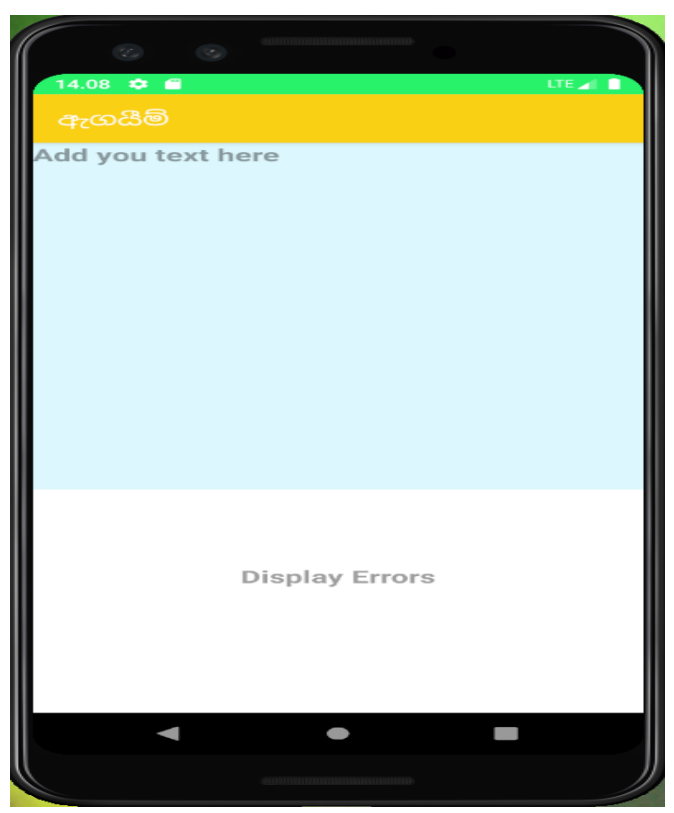

Figure 33 Spell Checking

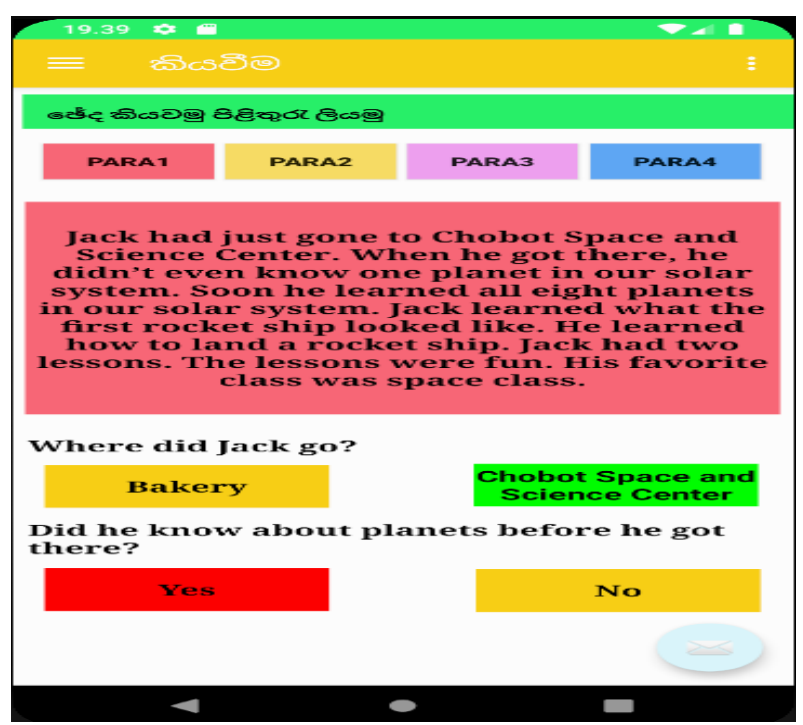

Figure 34 Paragraph reading

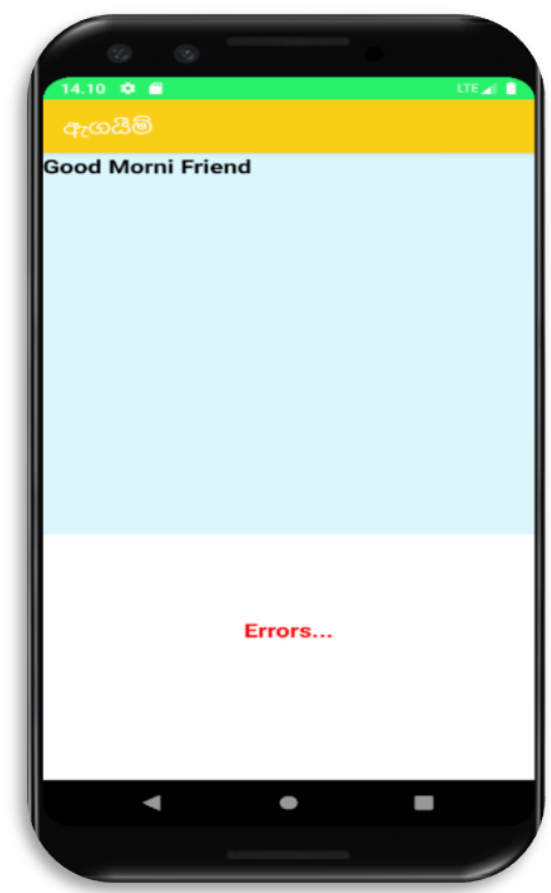

Figure 35 Spell Checking - with errors 


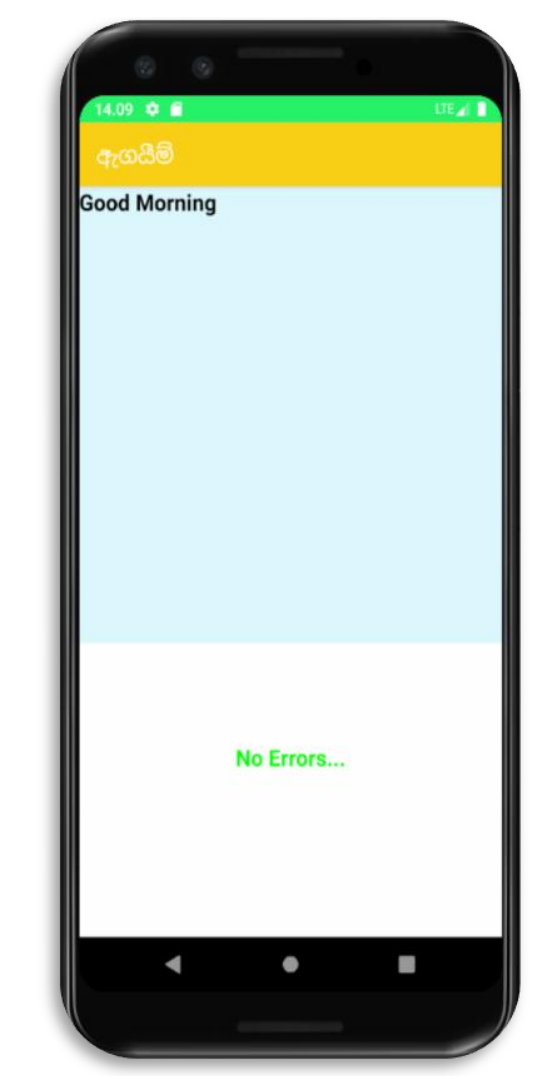

Figure 36 : Spell Checking - without errors

\section{A-6: Listening and Speaking}

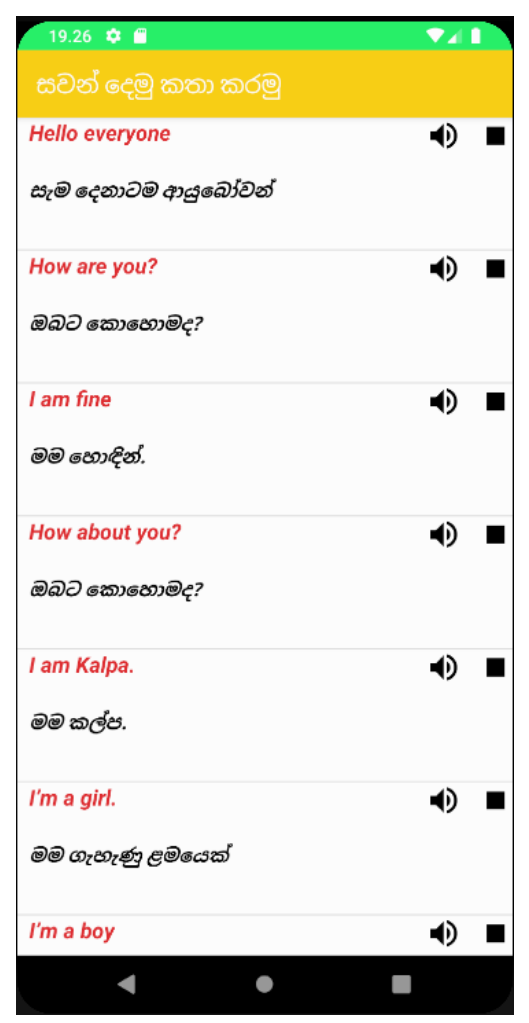

Figure 37 Listed audio clips with description 


\section{A-5 : Learn Vocabulary}

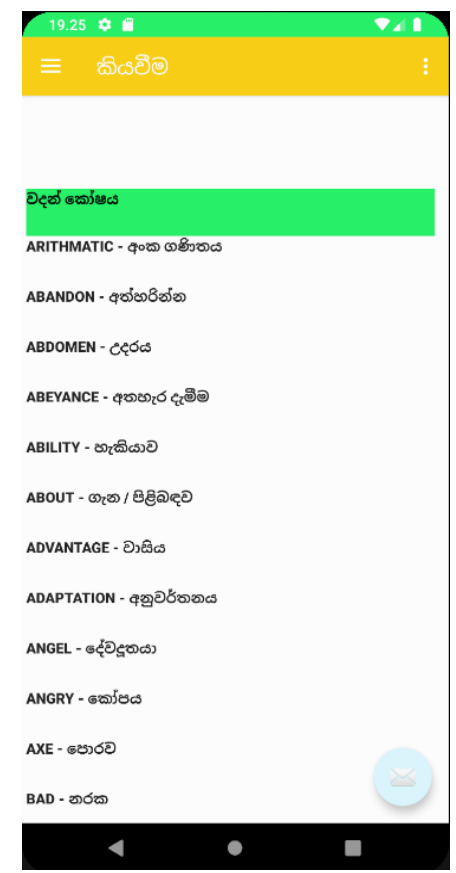

Figure 38 Vocabulary List

\section{A-7: Guide grammar and Essay writing.}

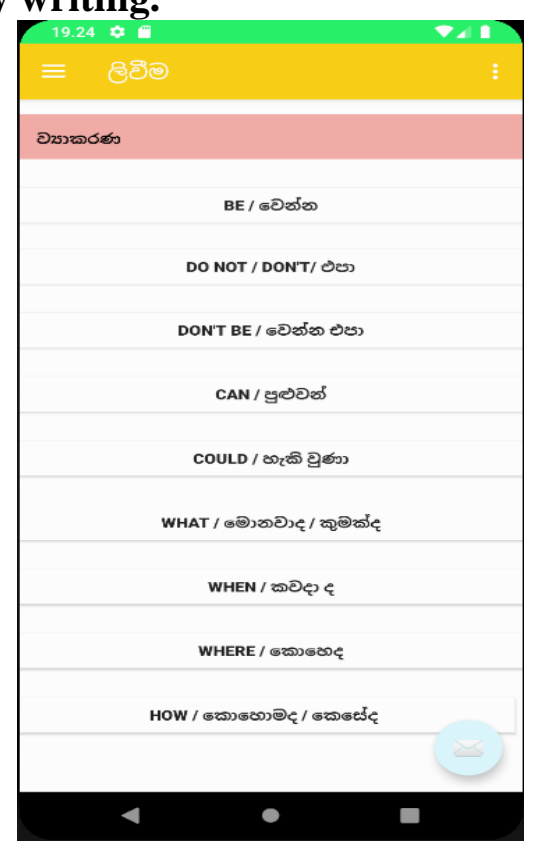

Figure 39: Grammar page 1 


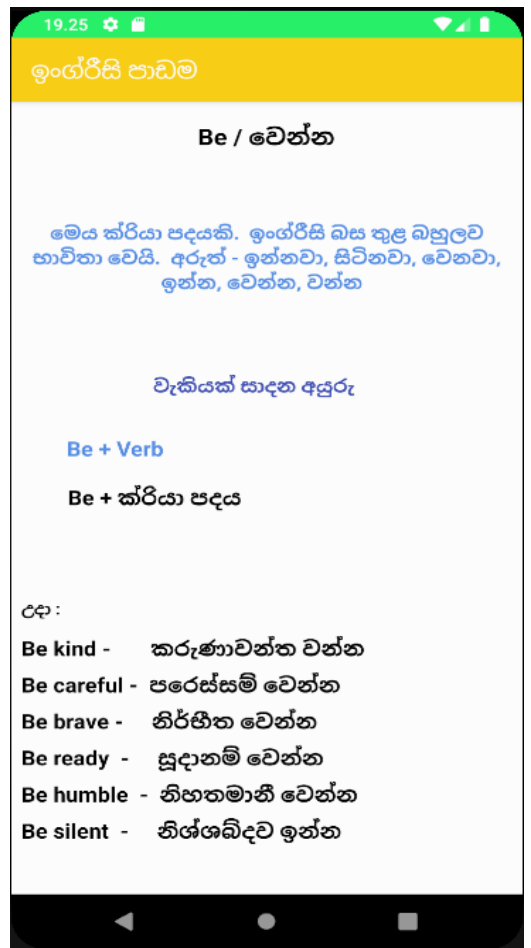

Figure 40: Grammar page 2

\section{Appendix B - Coding segments}

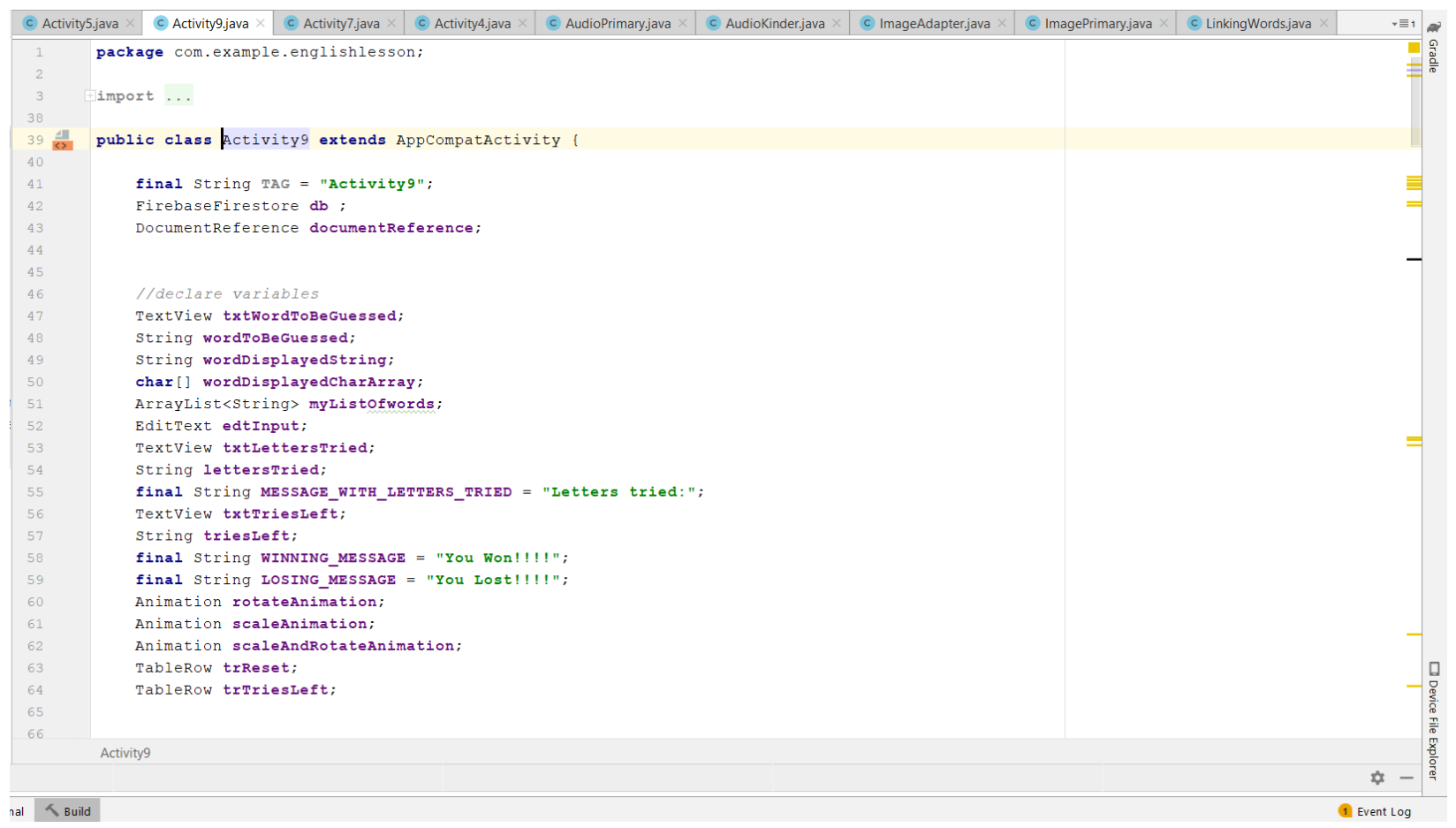

Figure 41 Figure 41 Code1 


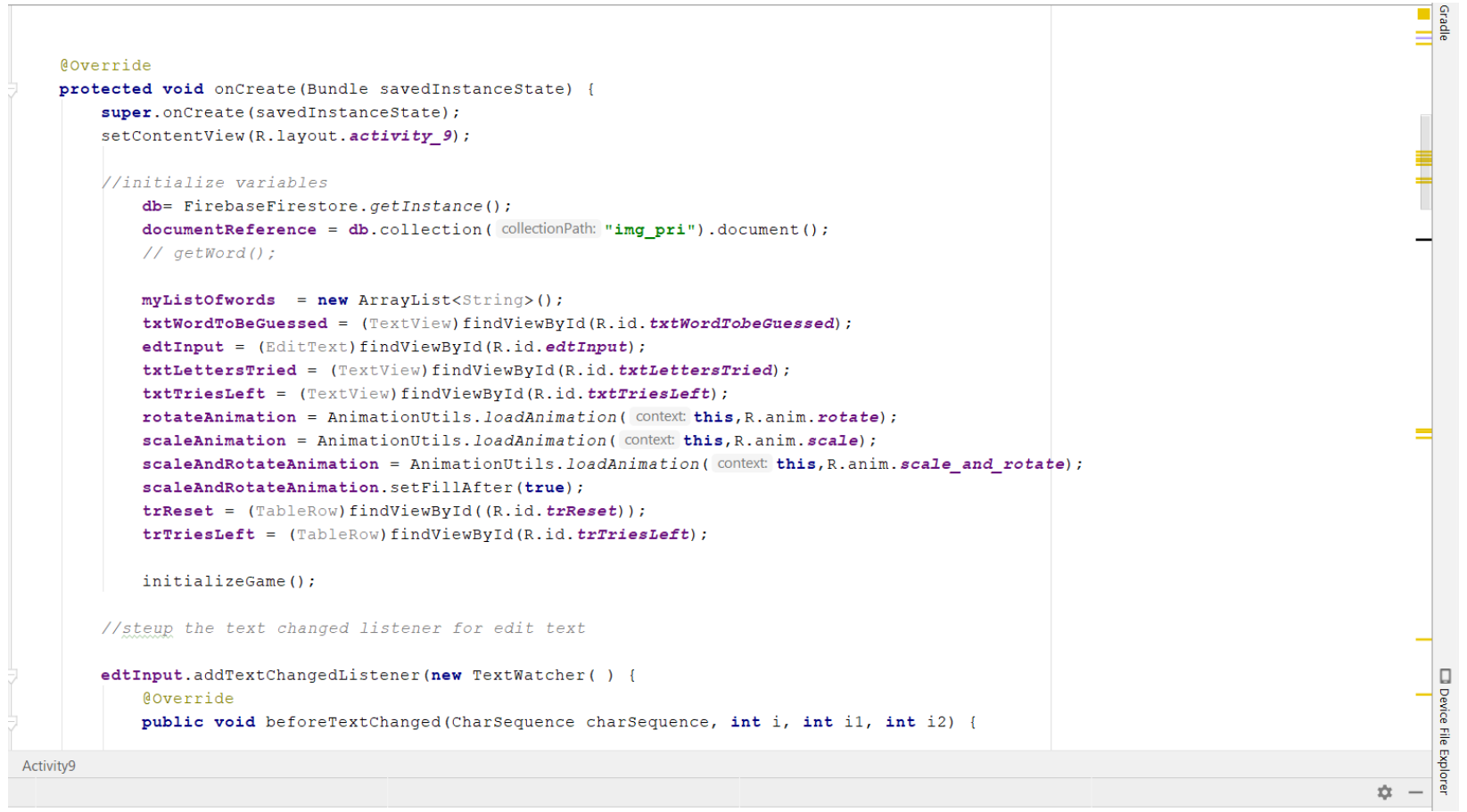

Figure 42 Code 2

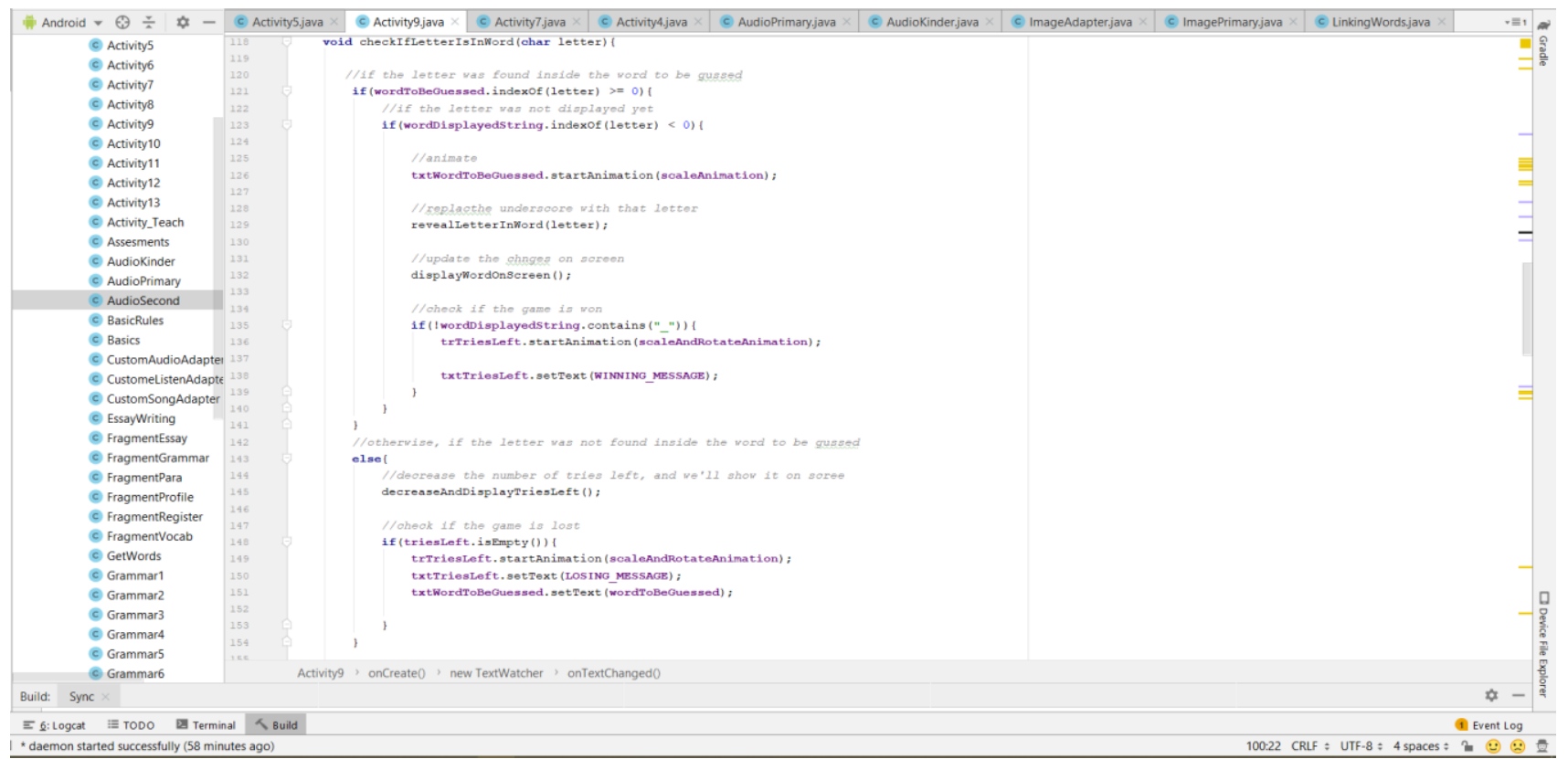

Figure 43 Code 4 


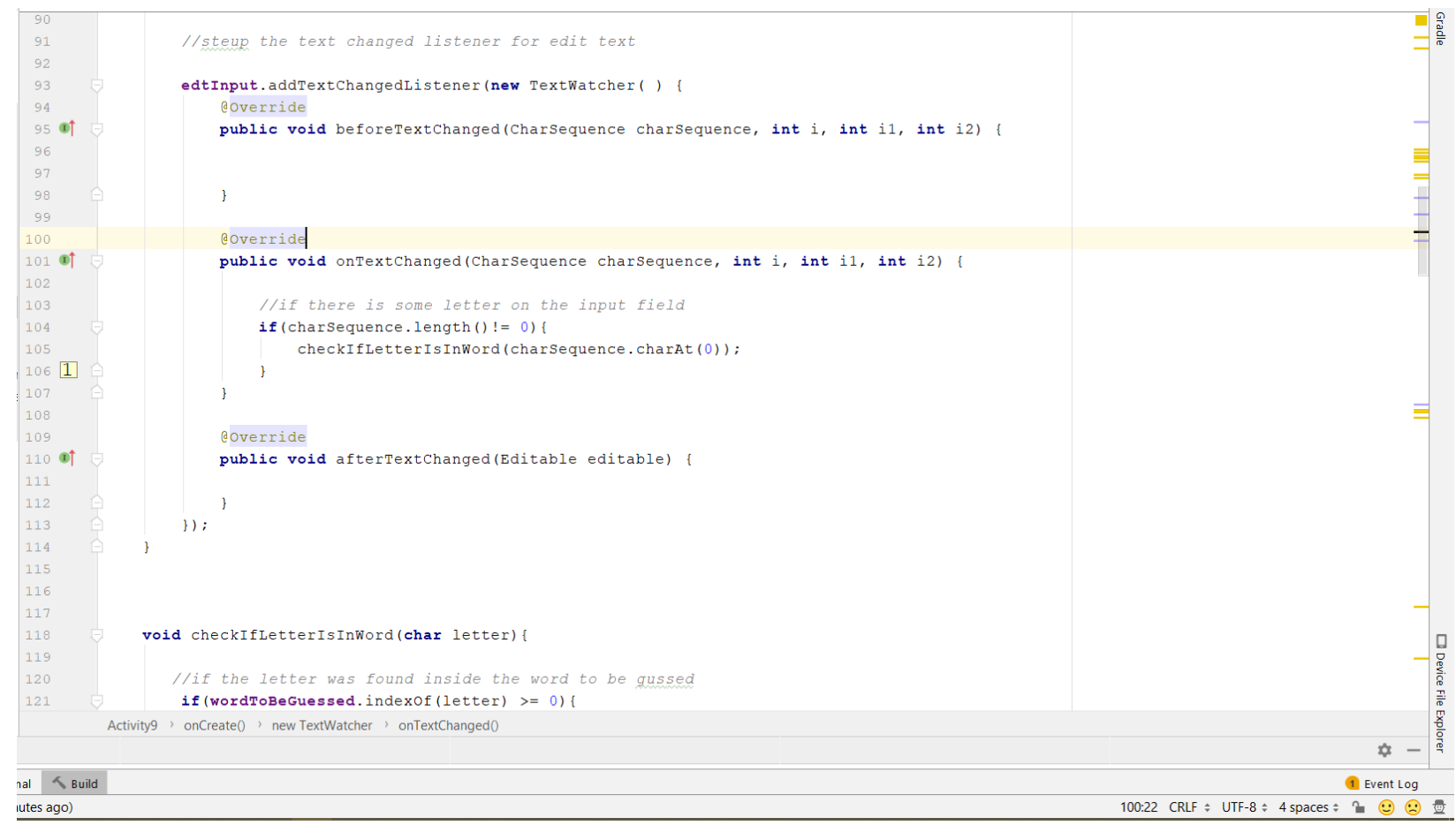

Figure 44 Code 3

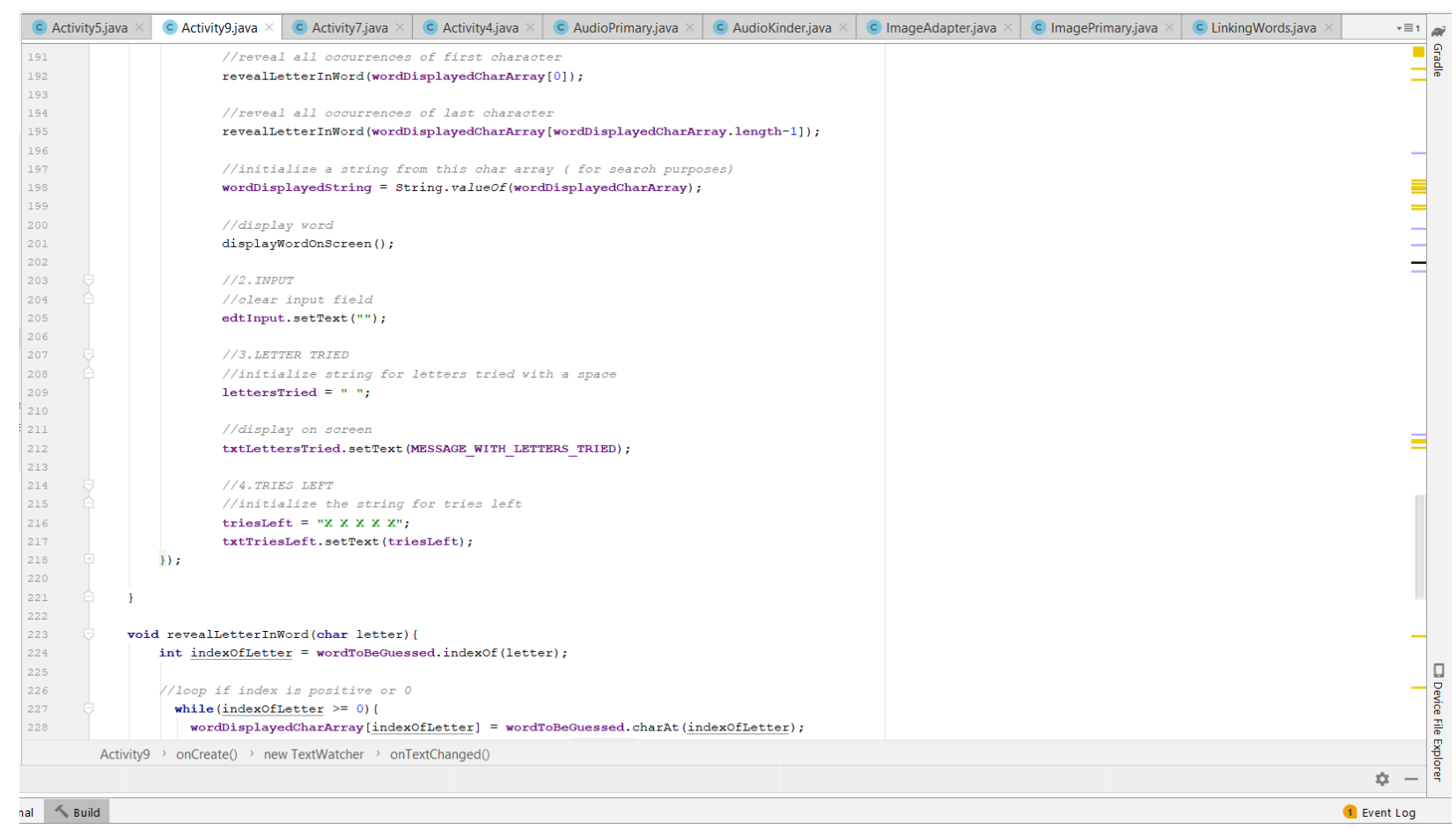

Figure 45 Code 6 
International Journal of Computer Applications (0975 - 8887)

Volume 177 - No. 13, October 2019

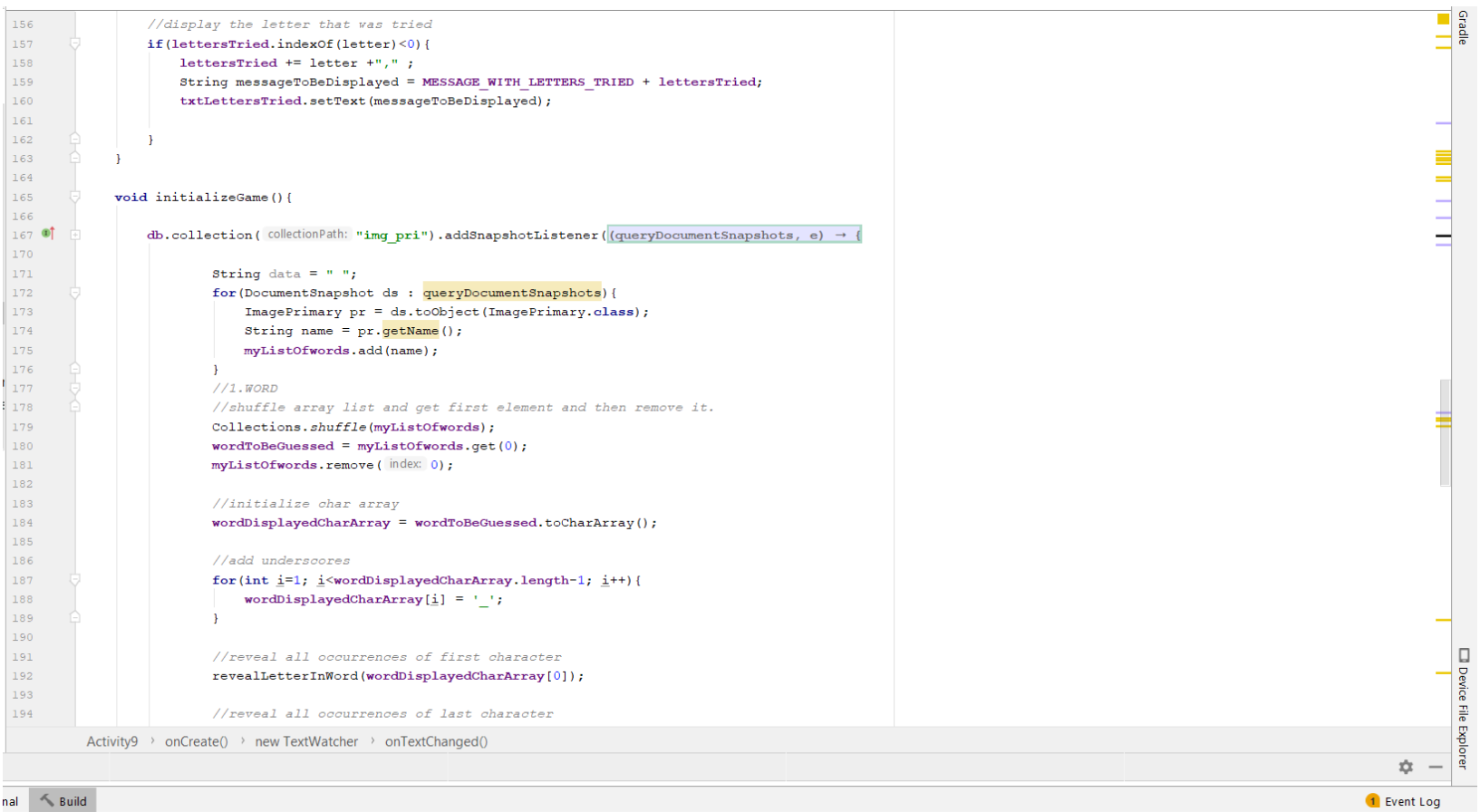

Figure 46 Code 5

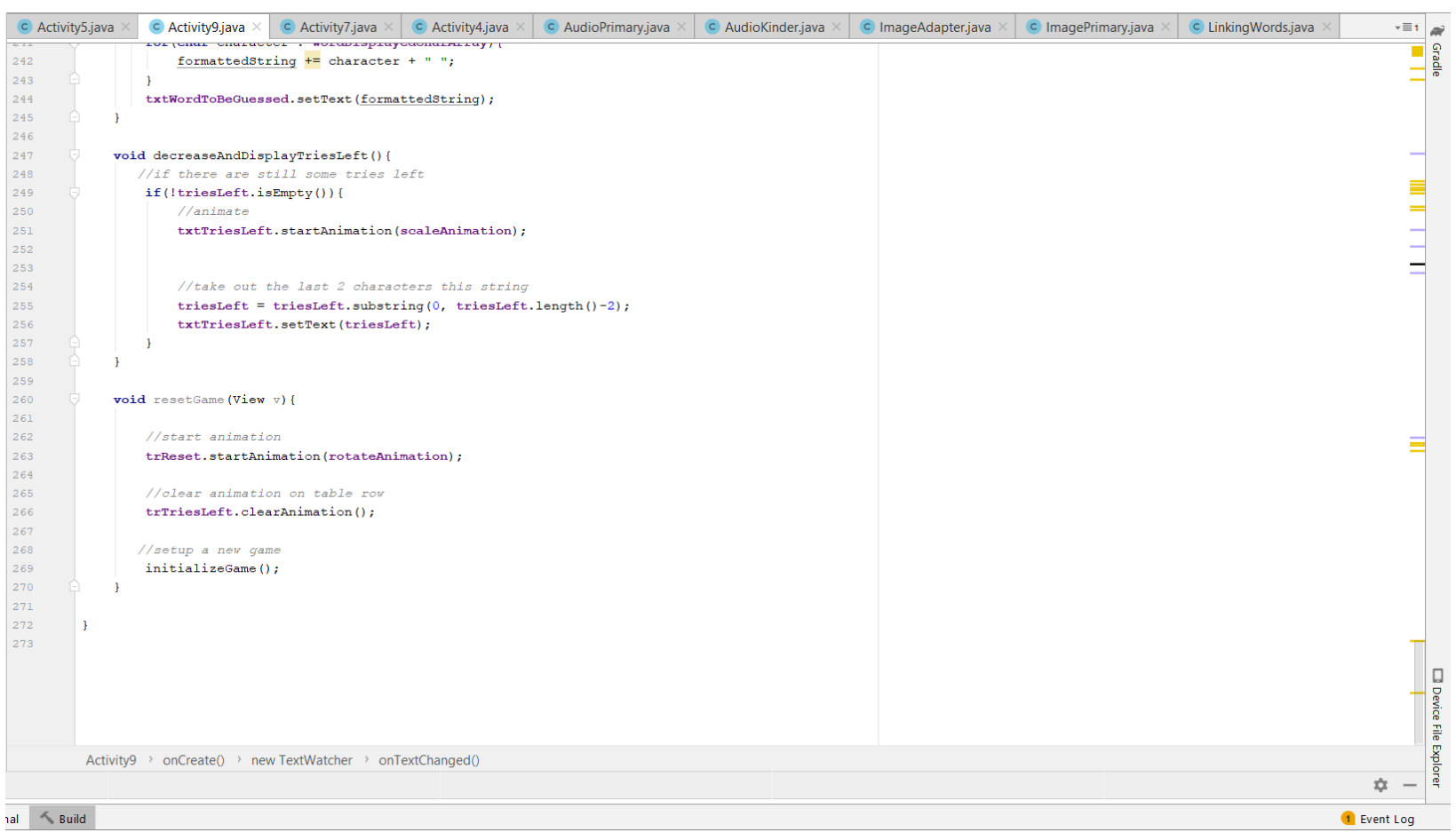

Figure 47 Code 8 


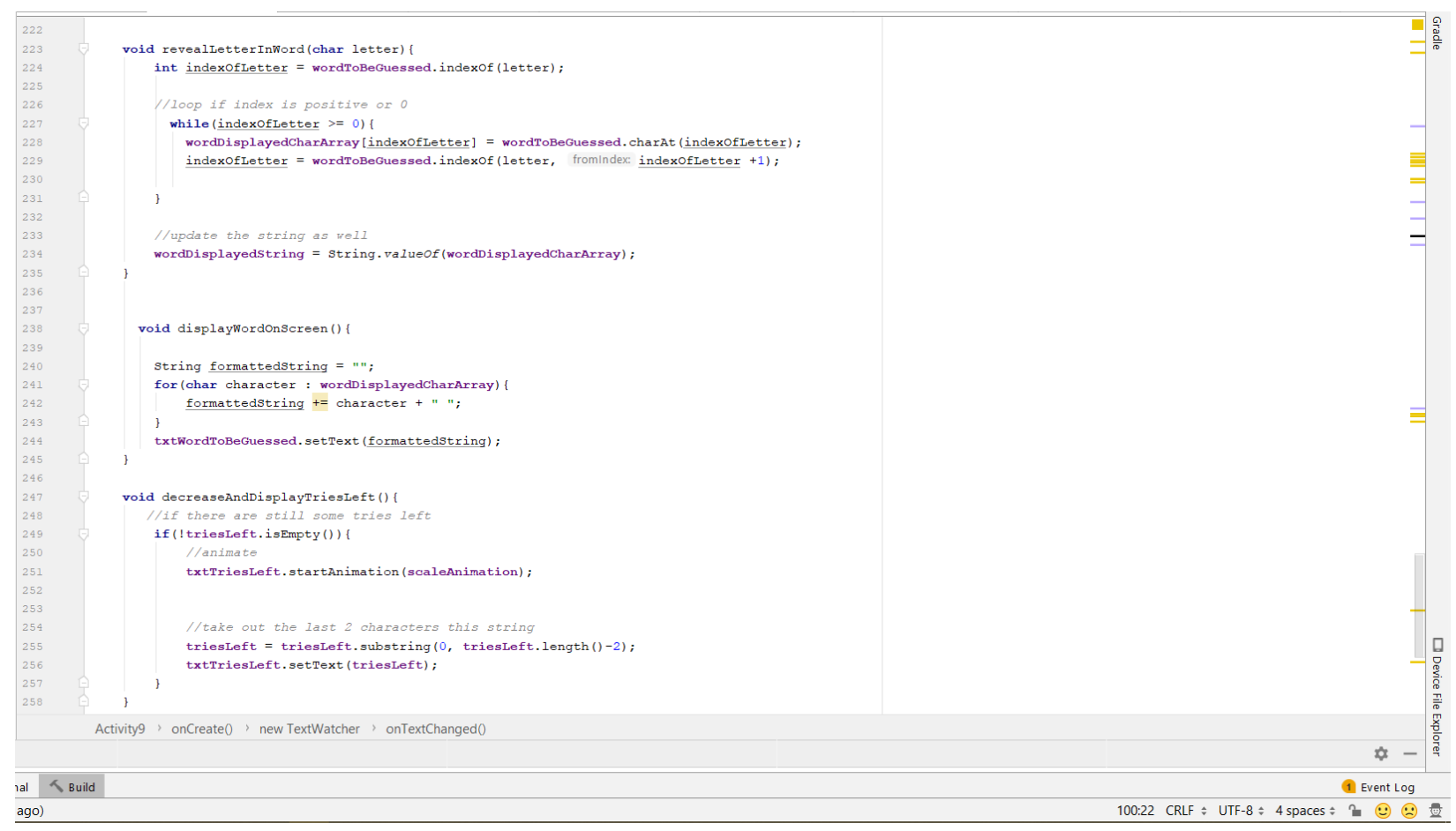

Figure 48 Code 7

\section{B-2: Reading paragraphs and answer questions}

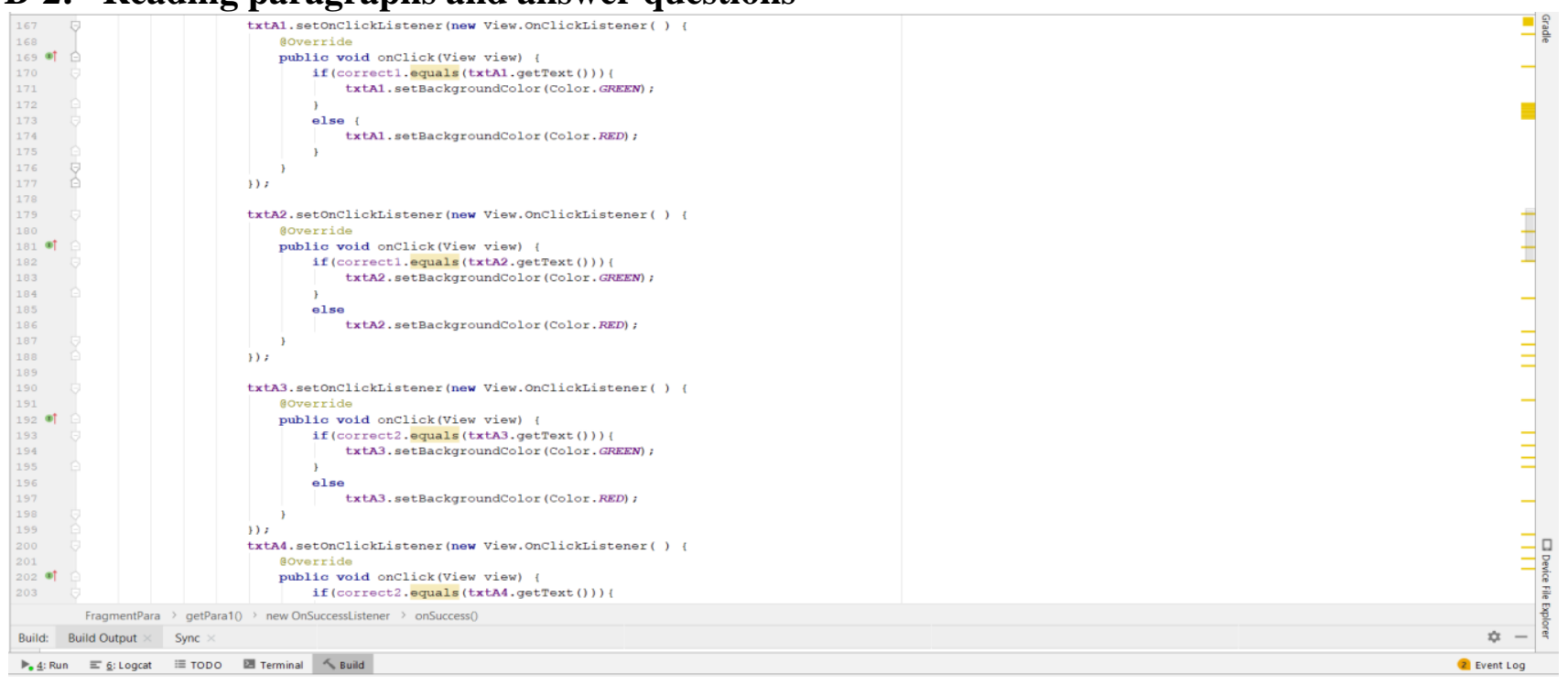

Figure 49 Code 2 


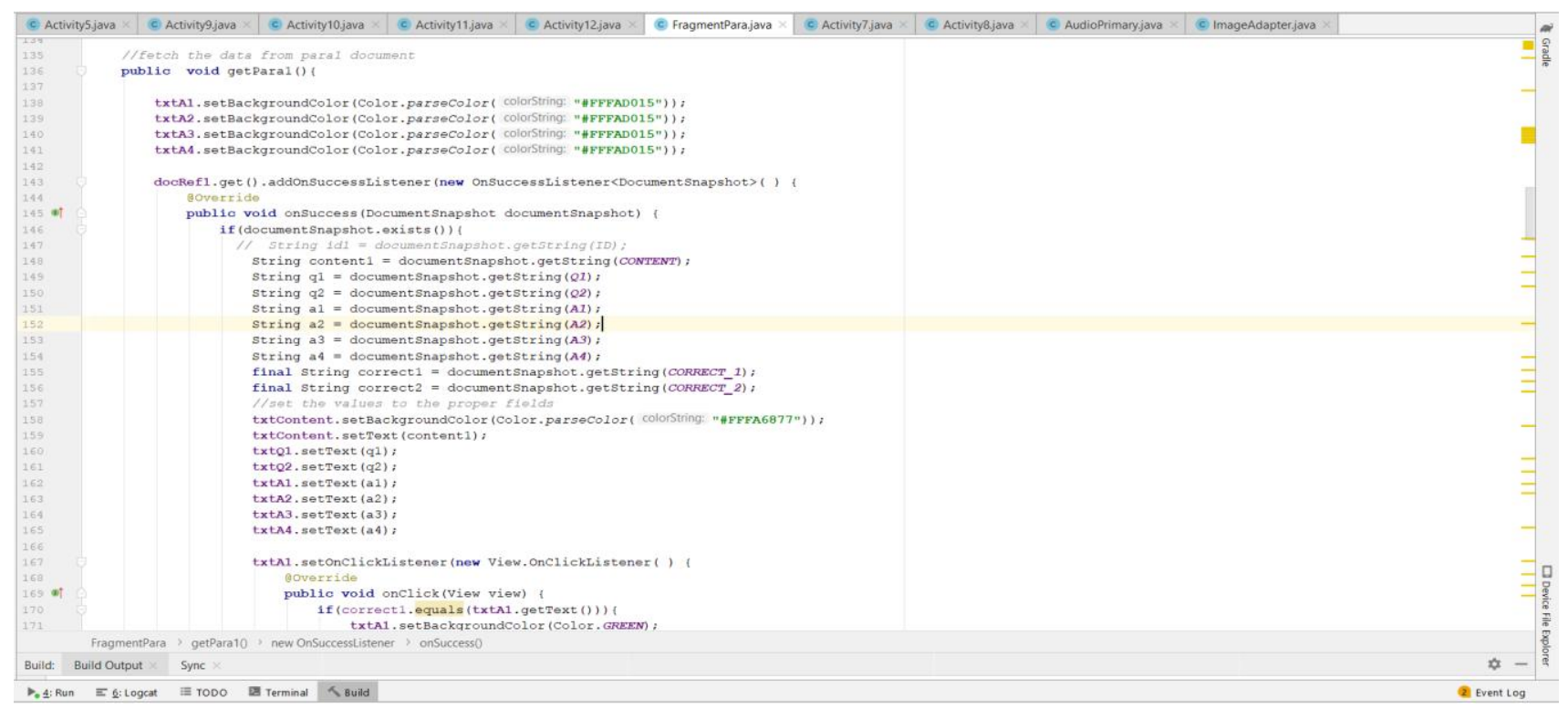

Figure 50 Code 1

\section{B-3: Spell checking for sentences}

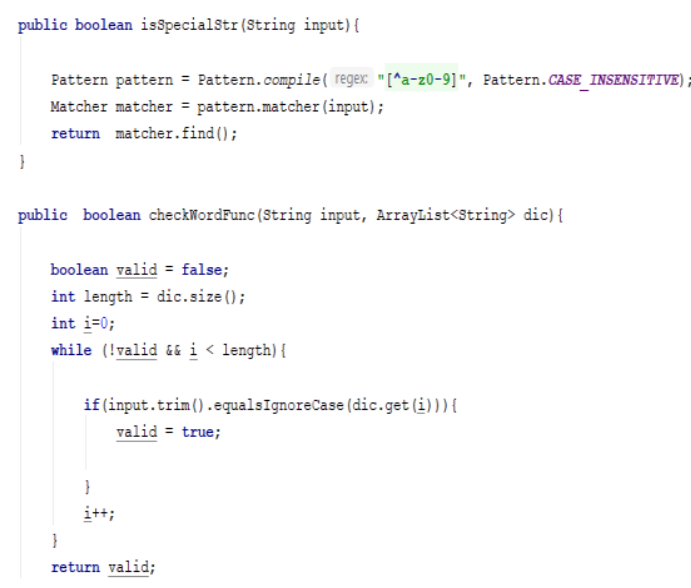

Figure 51 Code 2 
International Journal of Computer Applications (0975 - 8887)

Volume 177 - No. 13, October 2019

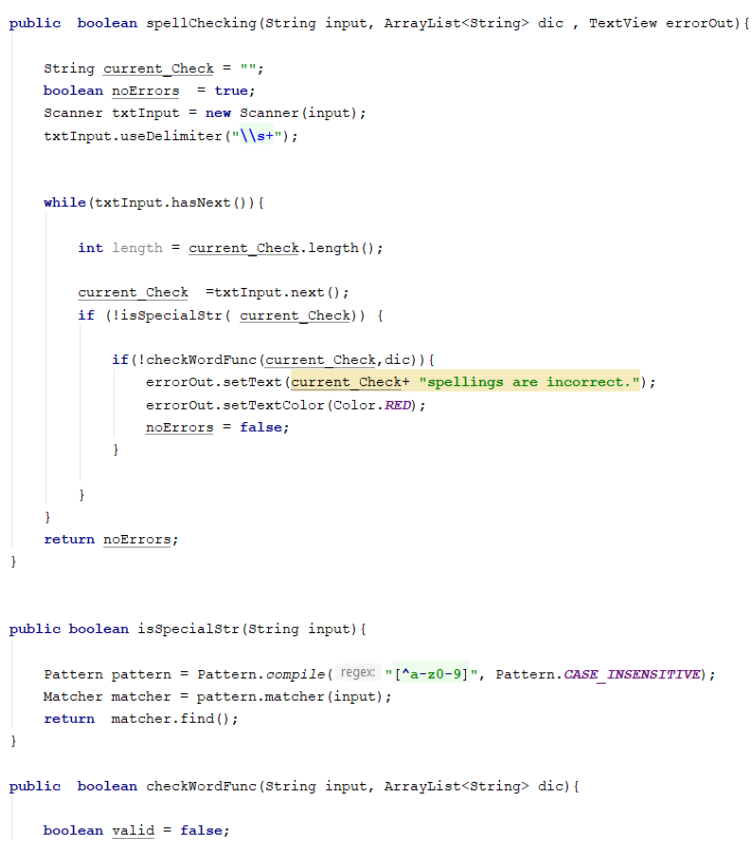

Figure 52 Code 1 